\title{
Simplified synthesis route for interfacially polymerized polyamide membranes
}

\author{
Sanne Hermans, Hanne Mariën, Elke Dom, Roy Bernstein, Ivo F.J. Vankelecom* \\ Centre for Surface Chemistry and Catalysis, Department of Molecular and Microbial Systems, \\ KU Leuven, Kasteelpark Arenberg 23, PO Box 2461, 3001 Leuven, Belgium \\ * Corresponding author: ivo.vankelecom@biw.kuleuven.be, tel: +3216321594
}

\begin{abstract}
A simplified method for the synthesis of thin film composite (TFC) membranes via interfacial polymerization was studied. Traditionally, the porous support layer is synthesized by phase inversion and subsequently impregnated with an aqueous amine solution before contacting it with an organic acyl chloride solution. In this simplified method, the phase inversion step and the impregnation with the amine monomer are carried out simultaneously by adding the amine to the coagulation bath before immersing the cast polymer film in it. This way, a two step process was successfully simplified into one step, combining both phase inversion and monomer impregnation of the support. Variation of synthesis parameters showed that a good membrane performance was achieved by adding $2 \mathrm{wt} \% \mathrm{~m}$-phenylenediamine (as a monomer), triethylamine and sodium dodecyl sulfate (as a base/acylation catalyst and surfactant, respectively) to the coagulation bath. These synthesis conditions accord with the ones used in the traditional method. However, the polysulfone concentration, used for the synthesis of the support layer, could be lowered in the simplified method, without compromising in membrane performance. This method could lead to a more efficient, time and material saving synthesis of TFC membranes, which is of potential interest from a commercial and environmental point of view.
\end{abstract}

\section{KEYWORDS}

Thin film composite

Interfacial polymerization

Aromatic polyamide

Membrane Synthesis

Nanofiltration 


\section{Introduction}

Interfacial polymerization is an established technique for the synthesis of thin film composite (TFC) membranes. Particularly, TFC membranes with a polyamide (PA) top layer are highly abundant for reverse osmosis (RO) and nanofiltration (NF) in aqueous applications. The PA active layer is synthesized on a polymeric support layer in two steps: First, the support layer is impregnated with an aqueous amine solution, and subsequently put into contact with an immiscible organic solvent that contains a second monomer, typically a hexane-based acyl chloride solution. At the interface between the two phases, both monomers react and form a very thin polymer layer of a few tens to hundreds nanometer thick [1]. The thin and highly crosslinked active layer together with its high ability to form hydrogen bonds, leads to high salt removal as well as high water permeance, robustness and durability, hence, superior membranes for aqueous applications. The porous support layer is generally an ultrafiltration (UF) poly(ether)sulfone membrane and the PA top layer is polymerized using m-phenylenediamine (MPD) or piperazine as amines and trimesoylchloride (TMC) as acyl chloride [2, 3]. Due to their vast usage, extensive research was conducted in order to optimize the conditions for the synthesis of PA membranes leading to membranes with an excellent performance in the desalination of brackish and sea water [4-9]. In addition, many researchers investigated the modification of the chemistry and morphology of the PA top layer to improve their performance and reduce their fouling propensity [10-15]. It was also demonstrated that several commercial membranes undergo surface modification during manufacturing [16, 17]. However, the fundamental procedure for the synthesis of a TFC membrane is virtually consistent. Hence, the aim of this research is to present a simplified route for the synthesis of a PA TFC membrane, while maintaining its excellent properties.

The support membrane, which is impregnated with the amine solution, is prepared using the phase inversion technique, in which a polymer solution is solidified by immersion in a coagulation bath consisting of a non-solvent, usually water [1]. It is therefore quite surprising that in open literature the phase inversion of the support and the impregnation with amine monomers in an aqueous solution are carried out separately. In this study, both steps are combined by using an aqueous amine solution as the coagulation bath for the polysulfone (PSf) support. It is suggested that by simplifying the two step process into one step (henceforth called the "SIM method"), the synthesis of TFC membranes will become faster and easier, which is of potential interest from a commercial point of view. In addition, it is assumed that a better quality of the formed PA layer might get realized (less pinhole defects), since each pore in the support already contains the diamine at its origin. The impregnation of a preformed support, as in the traditional method, might cause less efficient pore wetting, hence less reagent presence. To the best of our knowledge, this approach has not been reported before in the peer-reviewed literature. Only one rather old patent describes the process of quenching a PSf solution in an aqueous MPD solution to gel the PSf, form the porous support and impregnate the support with MPD [18]. The 
essential procedure described in this patent thus seems similar to the here reported SIM method. However, the patent remains vague about exact formulations used to synthesize the membranes (e.g. in the examples dimethylformamide (DMF) is also added to the coagulation bath). Therefore, a systematic study of this method, with clear comparison with state-of-the-art approaches, was performed in this paper.

Membrane characteristics of TFCs synthesized via the SIM method were compared to those of membranes synthesized via the traditional method. Then, the SIM method was thoroughly studied to clarify the effect of various parameters such as PSf and monomer concentration, presence of additives and immersion time in the coagulation bath, on its performance. The performance of the prepared membranes was analyzed using high throughput techniques [19-21]. In addition, the properties of the synthesized membranes were thoroughly characterized by SEM, TEM, ATR-FTIR, AFM and XPS in order to link their performance to their fundamental properties.

\section{Experimental}

\subsection{Materials}

Polysulfone (PSf, Udel ${ }^{\circledR}$ P-1700) was purchased from Solvay. The non-woven polypropylene/polyethylene (PP/PE) fabric Novatexx 2471 was kindly provided by Freudenberg (Germany). Trimesoylchloride (TMC, 98\%, Acros), meta-phenylenediamine (MPD, 99+\%, Acros), triethylamine (TEA, 99.5+\%, Sigma-Aldrich) and sodium dodecyl sulfate (SDS, 99\%, Acros) were used for interfacial polymerization. N-methylpyrrolidone (NMP, 99\%, Acros) and hexane (VWR, 97+\%) were used as received. Magnesium sulfate $\left(\mathrm{MgSO}_{4}\right.$, anhydrous, 99\%, Sigma-Aldrich) was applied as test solute. All experiments were carried out with Milli-Q water.

\subsection{Membrane synthesis}

\subsubsection{PSf support}

PSf UF membranes were synthesized via phase inversion. A homogeneous solution of PSf (dried overnight at $110^{\circ} \mathrm{C}$ ) in NMP was cast on a PP/PE non-woven, which was first impregnated with $\mathrm{NMP}$, at constant speed $(77 \mathrm{~mm} / \mathrm{s})$ using an automatic casting device (Braive Instruments, Belgium) at $200 \mu \mathrm{m}$ wet thickness.

To synthesize a membrane via the traditional process, the polymer film was immersed in distilled water for $10 \mathrm{~min}$. Hereafter, the membrane was rinsed for $5 \mathrm{~min}$ and stored in distilled water until further use.

To synthesize a membrane via the SIM method, the cast polymer film was immersed in an aqueous amine solution of 2 wt $\%$ MPD, 2 wt $\%$ TEA and 0.1 wt $\%$ SDS, unless specified otherwise. The coagulation time was 5 min when using the SIM method, unless specified otherwise. 


\subsubsection{Thin film composite}

A thin PA layer was synthesized on top of the PSf support via interfacial polymerization. When applying the traditional process for membrane preparation, the PSf support was first immersed in an aqueous amine solution of $2 \mathrm{wt} \%$ MPD, $2 \mathrm{wt} \%$ TEA and $0.1 \mathrm{wt} \%$ SDS for $5 \mathrm{~min}$. Hereafter, membrane synthesis based on the traditional process and the SIM method proceeded similarly. The excess aqueous solution was removed from the PSf membrane using a rubbery wiper. A solution of $0.1 \%(\mathrm{w} / \mathrm{v}) \mathrm{TMC}$ in hexane was subsequently poured gently on the impregnated support layer. The hexane solution was drained off after $60 \mathrm{~s}$ of polymerization and the membrane was rinsed with hexane to remove unreacted TMC. After $1 \mathrm{~min}$ air drying, the membrane was put in a water bath to remove unreacted MPD. Finally, the synthesized TFC membrane was stored in distilled water.

\subsection{Membrane characterization}

\subsubsection{Filtration experiments}

The filtration experiments were done with a high throughput filtration module, which allowed six simultaneous dead-end filtrations under the exact same operating conditions [19-21]. The active area of each membrane inside the module was $5.31 \cdot 10^{-4} \mathrm{~m}^{2}$. The feed was stirred rigorously at $400 \mathrm{rpm}$ to minimize concentration polarization. The membrane performance was tested with a 1 $\mathrm{g} / \mathrm{L} \mathrm{MgSO}_{4}$ solution in Milli-Q water. Every membrane was tested three times.

Membrane permeance $\left(\mathrm{L}_{\mathrm{p}}\right)$ was calculated using:

$$
\mathrm{L}_{\mathrm{p}}=\frac{\mathrm{V}}{\mathrm{A} \cdot \mathrm{t} \cdot \Delta \mathrm{P}}
$$

where, $\mathrm{V}$ is the permeate volume (L), $\mathrm{A}$ is the membrane area $\left(\mathrm{m}^{2}\right), \mathrm{t}$ is the time (h) and $\Delta \mathrm{P}$ is the applied pressure (bar).

The retention was calculated using:

$$
\mathrm{R}=\frac{\Lambda_{\mathrm{f}}-\Lambda_{\mathrm{p}}}{\Lambda_{\mathrm{f}}} \cdot 100
$$

in which $\Lambda_{\mathrm{f}}$ and $\Lambda_{\mathrm{p}}$ are the feed and the permeate conductivity (Consort C3010, Belgium), respectively.

A "porosity factor" $\varepsilon \cdot r^{2} p$ was defined for the PSf support membranes based on the HagenPoiseuille pore flow model:

$$
\mathrm{L}_{\mathrm{p}}=\frac{\varepsilon \cdot \mathrm{r}_{\mathrm{p}}}{8 \cdot \mu \cdot \delta_{\mathrm{m}}}
$$

where $L_{p}$ is the membrane permeance $\left(\mathrm{m}^{2} \cdot \mathrm{m}^{-1} \cdot \mathrm{Pa}^{-1} \cdot \mathrm{s}^{-1}\right), \varepsilon$ is the membrane porosity, $r_{p}$ is the pore radius $(\mathrm{m}), \mu$ is the solution viscosity ( $0.001 \mathrm{~Pa} \cdot \mathrm{s}$ for water at room temperature), and $\delta_{\mathrm{m}}$ is the 
membrane thickness (m), estimated from SEM cross-section images. Including both porosity and pore radius, this factor represents the overall effect of the pores on the permeance of the support membrane [22].

\subsubsection{Electron microscopy}

The cross-section morphology was analyzed with scanning electron microscopy (SEM), Philips XL 30 FEG SEM. Samples were broken in liquid nitrogen and coated with a thin $(1.5-2 \mathrm{~nm})$ gold layer using a Cressington HR208 high resolution sputter coater.

Transmission electron microscopy (TEM) was applied for top layer visualization at higher resolution. Unstained membrane samples were embedded in an araldite resin (Polyscience) and cut into ultrathin $(70 \mathrm{~nm})$ cross-sections with a Reichert Ultracut E microtome. Images were taken with a Zeiss EM900 TEM. Top layer thickness was calculated as the average of 20 equidistant spots along the entire cross-section.

\subsubsection{Atomic Force Microscopy (AFM)}

Membrane topographic images were acquired under water (TM Direct Drive holder) using a Dimension 3100 device (Bruker) in tapping mode with standard NC cantilevers (Nanosensors, PPP-NCHR, resonant frequency in air $\sim 320 \mathrm{kHz}$ ). Each sample was measured over an area of 25 $\mu \mathrm{m}^{2}$. The reported RMS roughness is the average of at least three different locations on each sample.

\subsubsection{Attenuated Total Reflectance Infra-Red (ATR-IR) Spectroscopy}

The chemical composition of the membrane surface was analyzed by ATR-FTIR. Spectra were collected from dried membranes using a Bruker ALPHA-P FT-IR spectrometer with a diamond ATR crystal. Thirty-two scans were collected at a resolution of $4 \mathrm{~cm}^{-1}$ and for every membrane at least three different positions were measured.

\subsubsection{X-ray photoelectron spectroscopy (XPS)}

To quantify the membrane surface elemental composition, XPS measurements were performed on a Physical Electronics PHI 1600 multi-technique system using an Al Ka (1486.6 eV) monochromatic X-ray source, which was operated at $200 \mathrm{~W}$. The spectra were taken with the electron emission angle at $45^{\circ}$ to give a sampling depth of $10 \mathrm{~nm}$. 


\section{Results and discussion}

\subsection{Comparison SIM and POST method}

In order to examine the possibility of using the SIM method for synthesis of a TFC PA membrane, TFC membranes were prepared using the traditional (henceforth called POST) and the SIM method at otherwise constant conditions, based on a previous study ( $2 \mathrm{wt} \% \mathrm{MPD}, 2$ wt $\%$ TEA, 0.1 wt $\%$ SDS in the aqueous solution and 0.1\% TMC in hexane) [22].

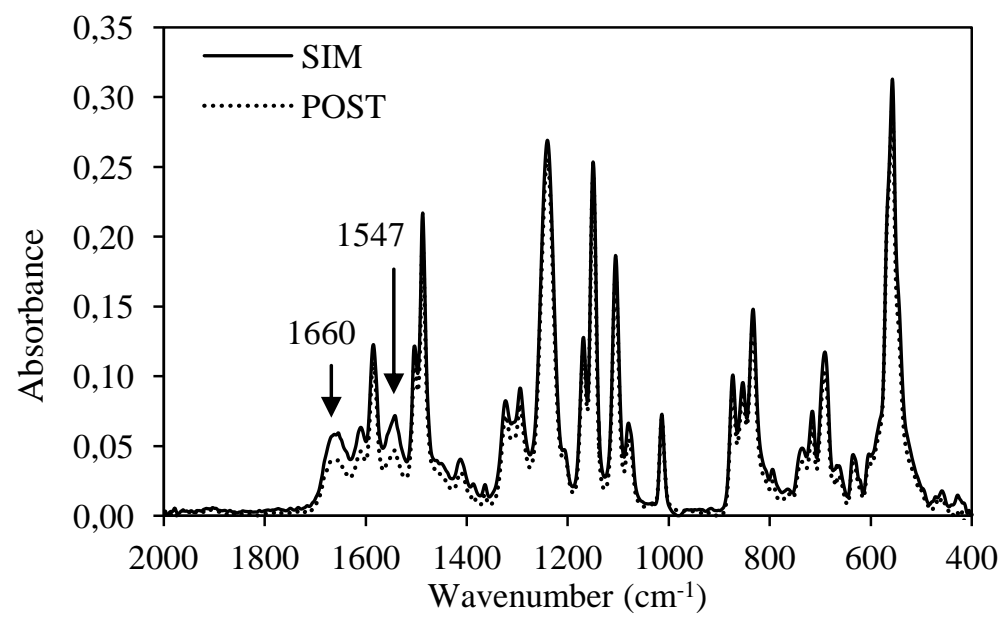

Figure 1: ATR-FTIR spectra of TFC PA membranes synthesized using the SIM method (full line) and the traditional POST method (dotted line). Synthesis conditions: 18 wt $\%$ PSf in casting solution, 2 wt $\%$ MPD, 2 wt $\%$ TEA and 0.1 wt $\%$ SDS in aqueous solution.

The IR spectra of the prepared membranes, measured using ATR-FTIR, overlap and the two typical bands assigned to the amide groups of PA at $1660 \mathrm{~cm}^{-1}\left(\mathrm{C}=\mathrm{O}\right.$ stretch) and $1547 \mathrm{~cm}^{-1}(\mathrm{NH}$ bend) are clearly seen in both cases (Figure 1). In addition, the POST and SIM membranes showed a similar surface and active layer morphology, as well as a similar active layer thickness (73 $\pm 26 \mathrm{~nm}$ for SIM, $75 \pm 18 \mathrm{~nm}$ for POST), as measured by SEM and TEM (Figure A in the supplementary information, SI). The performance (selectivity and permeance) of the two membranes was also similar: 96-97\% salt retention and $2.2-2.3 \mathrm{~L} \mathrm{~m}^{-1} \mathrm{~h}^{-1} \mathrm{bar}^{-1}$. Therefore, it was concluded that well-performing TFC PA membranes can be obtained by combining phase inversion and monomer impregnation of the support, hence, the SIM method can be used for the synthesis of these membranes.

\subsection{Effect of the SIM method on the support membrane}

\subsubsection{Coagulation time}

In the POST method, the already solidified support layer is usually impregnated with an amine solution for several minutes $[1,14,15]$. Since the proposed SIM method combines monomer impregnation with phase inversion of the support, the time needed to complete both processes 
was investigated. Both permeance and morphology of the support were found to be independent of the immersion time in the coagulation bath (5-60 min), which contained $2 \mathrm{wt} \% \mathrm{MPD}, 2 \mathrm{wt} \%$ TEA and $0.1 \mathrm{wt} \%$ SDS (Figure B and C in SI). Phase inversion is known to be a very fast process leading to membrane solidification [23]. The demixing stage, in which the polymer solution is separated into a polymer rich and lean phase, can be modified by additives [24-29]. Nevertheless, adding the reagents for the PA formation to the coagulation bath does not seem to influence the time needed for support formation. Therefore, polymer films were immersed in the coagulation bath for only $5 \mathrm{~min}$ in this study.

\subsubsection{Composition of casting solution and coagulation bath}

The addition of components (e.g. solvents or salts) to the non-solvent in the coagulation bath can influence the phase inversion process and hence the morphology of the formed membrane [30]. In addition, it is known that the morphology and pore size of the UF support membrane have a significant influence on the formation of a TFC PA membrane [7, 22, 31]. The synthesis of a TFC PA membrane usually requires additives, such as a base and a surfactant, to the aqueous phase. In this study, TEA and SDS, as a base/acylation catalyst and surfactant respectively, were added either separately or together to the coagulation bath containing MPD. Therefore, the effect of adding MPD (0.5 - $3 \mathrm{wt} \%$ ), TEA and SDS to the coagulation bath was investigated on the support membrane performance and morphology. Also, the effect of adding these components to the coagulation bath was investigated for casting solutions consisting of various PSf concentrations (14 - $22 \mathrm{wt} \%)$.

It was found that adding the components slightly increased the permeance of the support, but the effect was negligible (Figures D and E in SI). Hence, even with components in the coagulation bath, the prepared supports can be considered similar (same porosity factor) to the support prepared using only water in the coagulation bath. In addition, the similar SEM images of the support cross-sections with and without the addition of MPD, TEA and/or SDS (Figures F and G in SI) confirmed that the support membrane morphology was not influenced by the SIM method. Although nor MPD, TEA nor SDS are considered to be pore forming agents during the phase inversion process, it was somewhat surprising that none of these components had any significant effect on the support permeance. As expected, increasing the PSf concentration resulted in lower permeances (Figure $\mathrm{H}$ in SI), which were comparable to those of support membranes prepared in a coagulation bath of only water [22]. The cross-section morphology, obtained by SEM, also changed in a similar way as for membranes prepared in a coagulation bath of only water: higher PSf concentrations resulted in less macrovoids and slightly thicker dense areas above the macrovoids (Figure I in SI).

Thus, the phase inversion process of the support layer seems hardly affected by the addition of MPD, TEA or SDS to the coagulation bath, when comparing to phase inversion in a coagulation bath of pure water. Hence, the interfacial polymerization using the SIM method appears to be carried out on similar supports as those used for the POST method. Possible differences in the 
PA top layers are thus most probably not due to structural differences in the support layers but can merely be ascribed to the PA based top layer. Furthermore, it was not required to adjust the synthesis parameters using the SIM method in order to obtain a support with similar permeance and morphology as in the POST method. Therefore, the standard $18 \mathrm{wt} \%$ PSf casting solution, leading to a membrane porosity factor of $4.2 \cdot 10^{-16} \mathrm{~m}^{2}$, which was used in a previous study [22], was also applied now to study the SIM method.

\subsection{Effect of the SIM method on the TFC membrane}

The effect of preparing a TFC PA membrane using the SIM method was studied thoroughly. The synthesis conditions for the support membranes were chosen as discussed in the previous section. The TFC membranes were synthesized by changing one variable while keeping the others constant. The membrane performance, as well as the morphological and physicochemical properties, were investigated.

\subsubsection{MPD concentration}

Using the SIM method, the MPD monomer is thus impregnated inside the support layer during its solidification by phase inversion, hence, the monomer does not have to diffuse into the relatively hydrophobic PSf in a separate step. Because of this different synthesis aspect, it was first investigated which monomer concentration is required for the synthesis of a defect-free top layer using the SIM method. The performance of TFC PA membranes synthesized using various concentrations of MPD in the coagulation bath is presented in Figure 2. The salt retention ${ }^{1}$ increases from 45 to $96 \%$ with an increase in the MPD concentration from 0.5 to $2.0 \mathrm{wt} \%$ and then reaches a plateau value. The permeance shows a similar trend: an increase from 0.4 to $2 \mathrm{~L}$ $\mathrm{m}^{-1} \mathrm{~h}^{-1} \operatorname{bar}^{-1}$ (for 0.5 and $2.0 \mathrm{wt} \% \mathrm{MPD}$, respectively), where further increase in MPD concentration only had a minor effect.

\footnotetext{
${ }^{1}$ The reported salt retentions are those for $\mathrm{MgSO}_{4}$. The retention of a $2 \mathrm{~g} / \mathrm{L} \mathrm{NaCl}$ solution was measured for the TFC membrane prepared with $2.0 \mathrm{wt} \% \mathrm{MPD}$ and was found to be $92.7 \pm 0.8 \%$.
} 


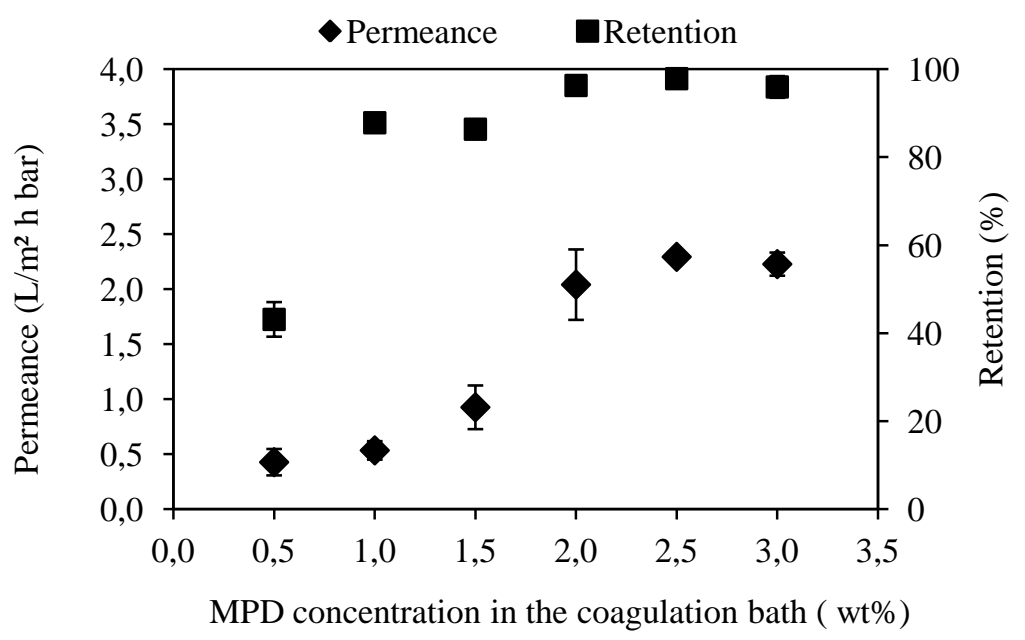

Figure 2: Water permeance and salt retention of TFC membranes synthesized via the SIM method with different MPD concentrations in the coagulation bath. Synthesis conditions: $18 \mathrm{wt} \%$ PSf in casting solution, ratio of MPD/TEA/SDS 2/2/0,1. Filtration conditions: 15 bar, $1 \mathrm{~g} / \mathrm{L} \mathrm{MgSO}_{4}$.

The standard deviations of both permeance and retention of the membranes prepared from 2.0 $\mathrm{wt} \%$ and $2.5 \mathrm{wt} \%$ MPD overlap partially, indicating that the difference between them is not statistically significant $\left(2.04 \pm 0.32 \mathrm{~L} \mathrm{~m}^{-2} \mathrm{~h}^{-1}\right.$ bar $^{-1}$ and $96.3 \pm 1.7 \% \mathrm{MgSO}_{4}$ retention when using $2.0 \mathrm{wt} \% \mathrm{MPD} ; 2.29 \pm 0.02 \mathrm{~L} \mathrm{~m}^{-2} \mathrm{~h}^{-1} \mathrm{bar}^{-1}$ and $97.8 \pm 0.8 \% \mathrm{MgSO}_{4}$ retention when using $2.5 \mathrm{wt} \%$ MPD). Keeping in mind that it is important for the production process to use the lowest possible amount of (hazardous) materials, $2.0 \mathrm{wt} \%$ MPD was thus chosen as the optimal MPD concentration using the SIM method. The commonly applied concentration of MPD monomer using the POST method with $0.1 \%$ TMC (as in this experiment) is also $2 \mathrm{wt} \%$ [1]. This implies that the MPD solution is successfully trapped in the formed pores of the PSf support during the phase inversion of the SIM process, in such a manner that its concentration in the support matrix is comparable to the one in the POST method.

Table 1: Elemental composition (in atomic percent) and ratios obtained by XPS and ratio between the intensity of an amide and a PSf peak (1660 and $1586 \mathrm{~cm}^{-1}$, respectively) measured by ATR-FTIR for TFC PA membranes synthesized via the SIM method using various MPD concentrations.

\begin{tabular}{lccccccc}
\hline MPD & $\mathrm{C}$ & $\mathrm{N}$ & $\mathrm{O}$ & $\mathrm{C} / \mathrm{N}$ & $\mathrm{C} / \mathrm{O}$ & $\mathrm{O} / \mathrm{N}$ & ATR-IR I $\mathrm{I}_{1660} / \mathrm{I}_{1586}$ \\
\hline $0.5 \mathrm{wt} \%$ & 67.7 & 8.7 & 23.5 & 7.8 & 2.9 & 2.7 & 0.05 \\
$1.5 \mathrm{wt} \%$ & 65.9 & 9.0 & 25.1 & 7.3 & 2.6 & 2.8 & 0.11 \\
$3.0 \mathrm{wt} \%$ & 70.7 & 11.1 & 18.3 & 6.4 & 3.9 & 1.6 & 0.32 \\
$\begin{array}{l}\text { Theoretical cross- } \\
\text { linked PA }\end{array}$ & 75.0 & 12.5 & 12.5 & 6.0 & 6.0 & 1.0 & - \\
$\begin{array}{l}\text { Commercial PA } \\
\text { membrane }\end{array}$ & 73.1 & 10.2 & 16.7 & 7.2 & 4.4 & 1.6 & - \\
\hline $\begin{array}{l}\text { Itaken from [32]. } \\
\text { takn }\end{array}$ & & & & & &
\end{tabular}

Based on the ATR-FTIR spectra of these TFC PA membranes, the ratio between the intensities of the PA peak $\left(1660 \mathrm{~cm}^{-1}\right)$ and a peak of the aromatic ring of the PSf support membrane (1586 
$\mathrm{cm}^{-1}$ ) was calculated in order to evaluate the PA formation, as presented in Table 1 (spectra shown in Figure $\mathbf{J}$ of SI). It is noted that the PSf peak was not constant for the different TFC top layers, but the ratio enables to acquire at least qualitative information. The higher ratio with increasing MPD concentration in the coagulation bath suggests that the amide concentration in the active layer or the PA thickness increase when higher amounts of amine are applied inside the support pores. When the amine concentration is less than $2 \mathrm{wt} \%$, it is probably too low to obtain a defect-free polymerized active layer. To study the chemical composition of the active layer more closely, XPS experiments were performed. Table 1 lists the elemental composition of the active layer. A fully cross-linked aromatic PA layer consists of a theoretical C:N:O composition of 75:12.5:12.5; however, as was demonstrated previously, this ratio can vary due to polymerization conditions [17]. From the three membranes that were examined (prepared using $0.5,1.5$ and $3 \mathrm{wt} \% \mathrm{MPD})$, only the one with $3 \mathrm{wt} \% \mathrm{MPD}$ had elemental ratios (C/O and O/N) comparable to a commercial PA membrane [32]. The higher ratios of $\mathrm{C} / \mathrm{N}$ and $\mathrm{O} / \mathrm{N}$ for membranes prepared using 0.5 and $1.5 \mathrm{wt} \%$ MPD can be assigned to higher concentrations of carboxyl acid in the active layer surface, hence less cross-linking [16]. This effect was not detectable in the IR spectra since XPS measures the chemical composition in the outmost layer (about $10 \mathrm{~nm}$ thick), whereas the penetration depth of the evanescent wave in the ATR element is approximately $1 \mu \mathrm{m}$.
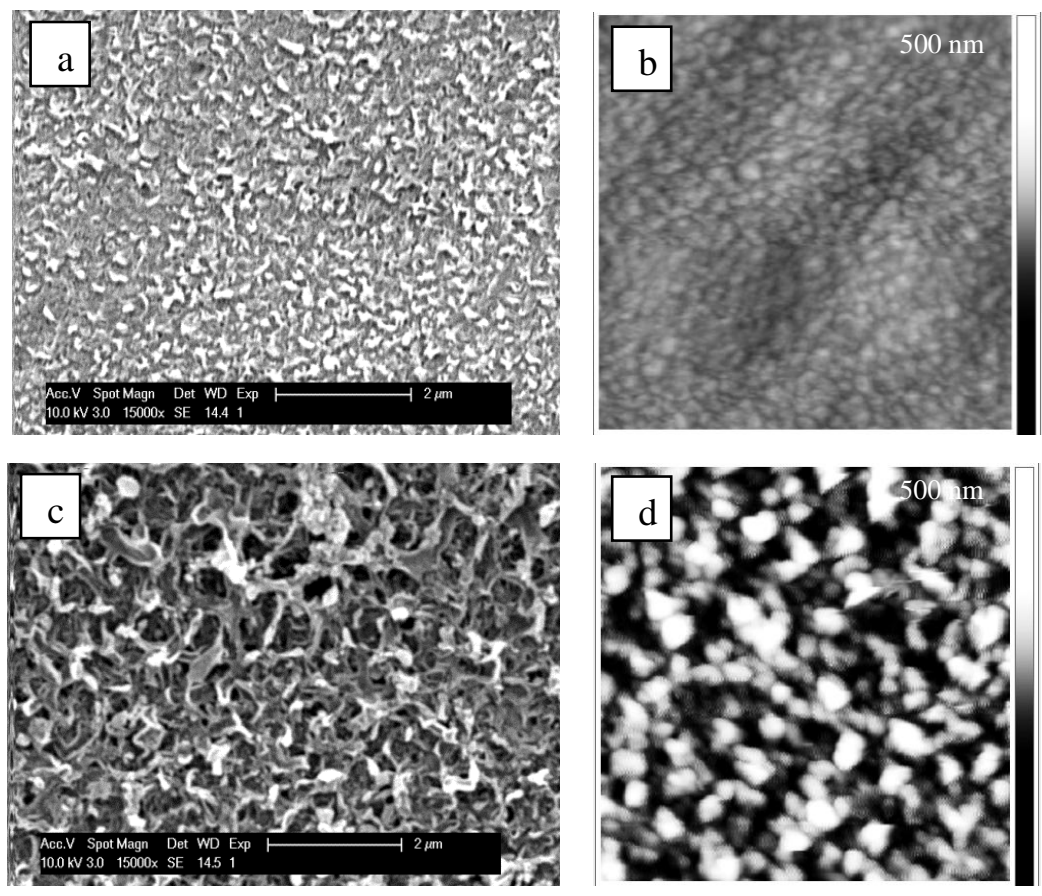

Figure 3: Surface SEM images (a, c) and water immersed AFM images (b, d) of TFC PA membranes synthesized using the SIM method with $0.5 \mathrm{wt} \%$ MPD $(\mathrm{a}, \mathrm{b})$ and $3.0 \mathrm{wt} \%$ MPD (c, d).

The changes in the active layer morphology due to different MPD concentrations were studied with SEM and water immersed AFM. Lowering the MPD concentration in the coagulation bath changed the surface morphology, as clearly seen in Figure 3. Using an MPD concentration of 0.5 
$\mathrm{wt} \%$ resulted in a less pronounced ridge and valley morphology with a roughness of $16 \pm 2 \mathrm{~nm}$, which is much lower than for TFCs synthesized using $3 \mathrm{wt} \%$ MPD, which had a roughness of 61 $\pm 7 \mathrm{~nm}$, similar to commercial PA membranes [33]. Moreover, the PA layer thickness, as measured by TEM images (Figure 4), increased from $32 \pm 16 \mathrm{~nm}$ for $0.5 \mathrm{wt} \%$ MPD, to $59 \pm 28$ $\mathrm{nm}$ and $149 \pm 46 \mathrm{~nm}$ for $1.5 \mathrm{wt} \%$ and $3 \mathrm{wt} \%$ MPD, respectively.
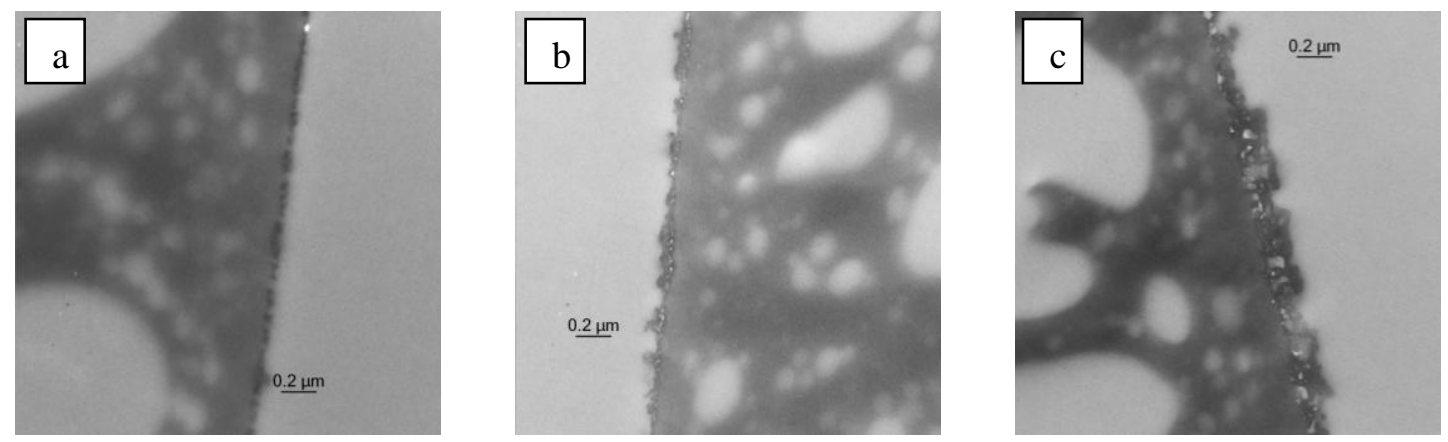

Figure 4: Cross-section TEM images of TFC PA membranes synthesized via the SIM method with different MPD concentrations in the coagulation bath: (a) $0.5 \mathrm{wt} \%$, (b) $1.5 \mathrm{wt} \%$ and (c) $3.0 \mathrm{wt} \%$. Synthesis conditions: $18 \mathrm{wt} \% \mathrm{PSf}$ in casting solution, ratio of MPD/TEA/SDS 2/2/0,1.

The relatively rough active layer morphology, characterized by the typical ridge and valley morphology of an aromatic PA membrane synthesized using the POST method originates from the PA growth toward the organic phase [4, 34, 35]. Chai et al. suggested that low MPD concentrations cause the film to grow toward the aqueous phase (rather than toward the organic phase), perhaps due to less diffusion of the amine to the organic phase caused by the lower concentration gradient of MPD [9]. This then results in a thinner, less rough and probably defective active layer. It was also shown by Matthews et al. that PA forms predominately within the pores of PSf at low MPD concentrations [36]. The smooth 'grainy' surface morphology following PA formation using the SIM method with MPD concentrations below $2 \mathrm{wt} \%$, is in agreement with these assumptions and can explain the low permeance and low retention of these membranes, due to blocking of PSf pores and defects in the PA layer, respectively.

Based on the experimental and characterization evidence, it can be concluded that MPD concentrations lower than $2 \mathrm{wt} \%$ produce inadequate membranes when using the SIM method. It can be found in literature that this is also true for membranes prepared following the POST method. Saha et al. studied the MPD-TMC system and found the same trend of increasing flux and salt retention with increasing MPD concentration [15]. Xie et al. found an optimum performance for an MPD concentration of 1.5 - $2.0 \mathrm{wt} \%$ [37]. They suggested that higher MPD concentrations increase the driving force for MPD diffusion, hence produce thicker barrier layers with lower permeances. When the MPD concentration decreases, they expected a thinner barrier layer with higher permeance, but claimed that another effect plays an important role: the barrier layer can become more dense for lower MPD concentrations because the molar ratio of amine/acyl chloride gets closer to unity, which would lower permeance, according to Freger et al. [38, 39]. Their assumptions of varying barrier layer thickness are confirmed in this study (see 
Figure 4), and by Chai et al. [9]. However, the assumption of a denser network when applying lower MPD concentrations, is not in agreement with our finding, i.e. lower MPD concentrations produce less cross-linked top layers (see Table 1). Nevertheless, their optimum MPD concentration is similar to the one found in this work. Moreover, the pioneering work of Cadotte, which led to the development of the commercial FT-30 membrane, states that the optimum concentration of phenylenediamine appears to be about $2 \mathrm{wt} \%$ [40].

\subsubsection{Additives}

As mentioned earlier, additives can be put in the aqueous amine solution during the synthesis of a TFC PA membrane. Based on previous studies [22, 41], TEA and/or SDS were added in these experiments. The ATR-IR spectra for all TFC membranes were similar, indicating that no significant change in the chemical composition of the active layer took place (Figure $\mathrm{K}$ in SI).

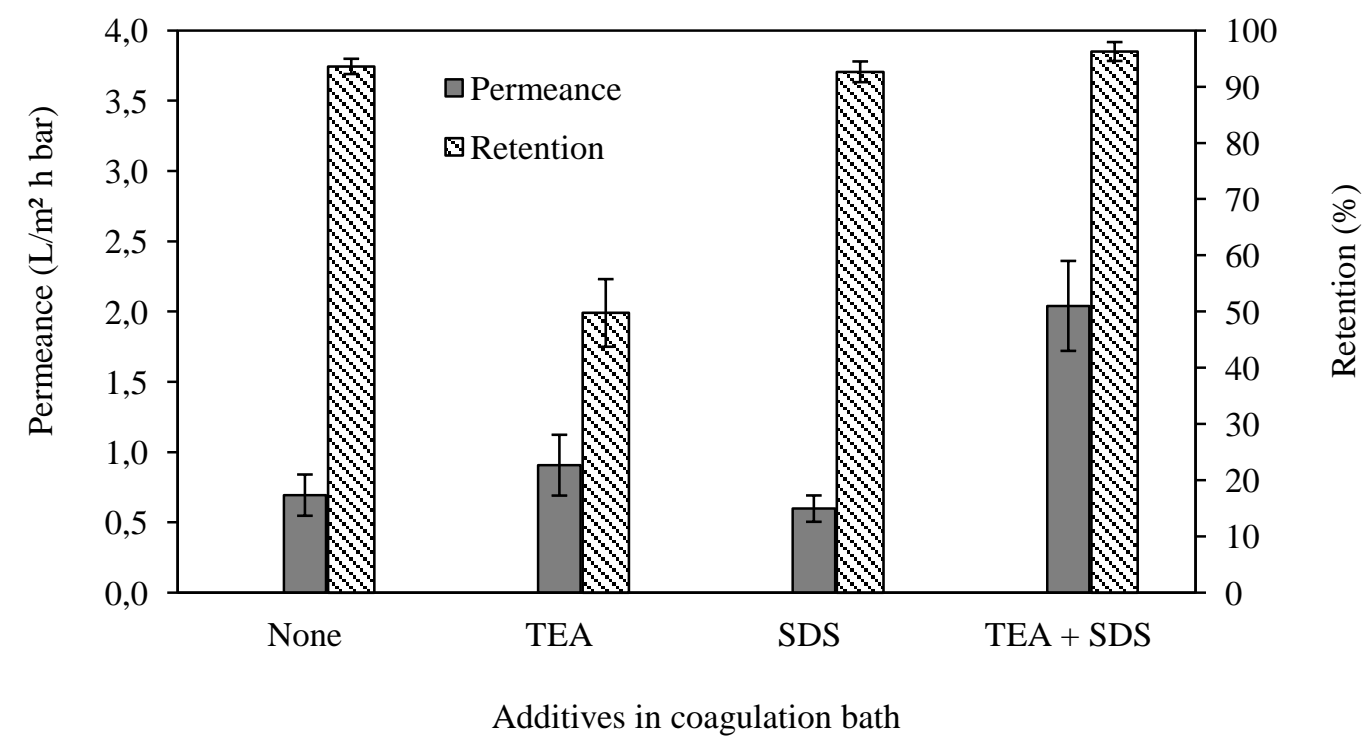

Figure 5: The effect of using additives (TEA and SDS) to the coagulation bath containing MPD on the water permeance and salt retention of TFC membranes synthesized using the SIM method. Synthesis condition: $18 \mathrm{wt} \%$ PSf in casting solution. Filtration conditions: 15 bar, $1 \mathrm{~g} / \mathrm{L} \mathrm{MgSO}_{4}$.

The membrane synthesized without additives already shows a reasonable retention (94\%), but its permeance is only $0.69 \mathrm{~L} \mathrm{~m}^{-1} \mathrm{~h}^{-1} \mathrm{bar}^{-1}$ (Figure 5, None). Based on the performance of the membranes, only SDS had almost no effect, whereas adding only TEA resulted in a worse performance. Adding the two additives together had a clearly positive effect on both the water permeance and the selectivity (Figure 5, TEA+SDS).

It is accepted that a base, such as TEA, is often added in order to capture the $\mathrm{HCl}$ which is formed during the polymerization of MPD and TMC [4, 14]. Moreover, it was proposed that TEA can accelerate the PA formation due to its catalytic properties [22]. On the other hand, it was previously demonstrated that the addition of TEA as a sole additive did not improve the performance of TFC PA membranes prepared using the POST method [1,22]. Using the SIM 
method, adding TEA to the coagulation bath indeed also significantly reduced the membrane performance. Since mainly the retention is affected, it may be suggested that TEA causes the formation of small defects in the active layer.

It was previously suggested that surfactants like SDS facilitate the impregnation of the amine solution into the pores of the rather hydrophobic support membrane [4, 42]. However, in the SIM method phase inversion and impregnation with amines are carried out simultaneously, i.e. the pores are already filled with the amine solution during their formation. This could explain why the addition of SDS had no beneficial effect in these experiments. Additionally, as a surfactant, SDS also lowers the surface tension at the interface between the aqueous and the organic phase [43]. Consequently, the polymerization rate can increase. However, without the presence of TEA, which also accelerates the reaction rate, this effect is likely not significant enough to influence the membrane performance.

In agreement with our previous study [22], adding both TEA+SDS showed a synergetic effect on the membrane formation, as seen from its strong performance. The solute passage (i.e., 1retention) decreased by $42 \%$, while the water permeance was more than three times higher (from 0.69 to $2.04 \mathrm{~L} \mathrm{~m}^{-1} \mathrm{~h}^{-1} \mathrm{bar}^{-1}$ ). Both TEA and SDS increase the polymerization rate, but perhaps a critical combination of both additives is needed to obtain a positive effect on the membrane performance. It is assumed that adding SDS does not only increase the transport of MPD toward the organic phase, but also increases the transport of TEA, leading to higher amounts of base/catalyst in the reaction zone (situated slightly more toward the organic phase). A large increase in the polymerization rate is known to result in a thinner film, which can explain the higher permeance [35]. Moreover, the higher reaction rate could result in a more open top layer structure since the PA chains have less time to get properly organized, which could also explain the increased permeance. Because of the less dense PA structure, the polymerization could possibly proceed longer before the diffusion of MPD to the reaction zone becomes rate-limiting. Perhaps, this way a higher degree of cross-linking can be achieved, causing the increase in retention.

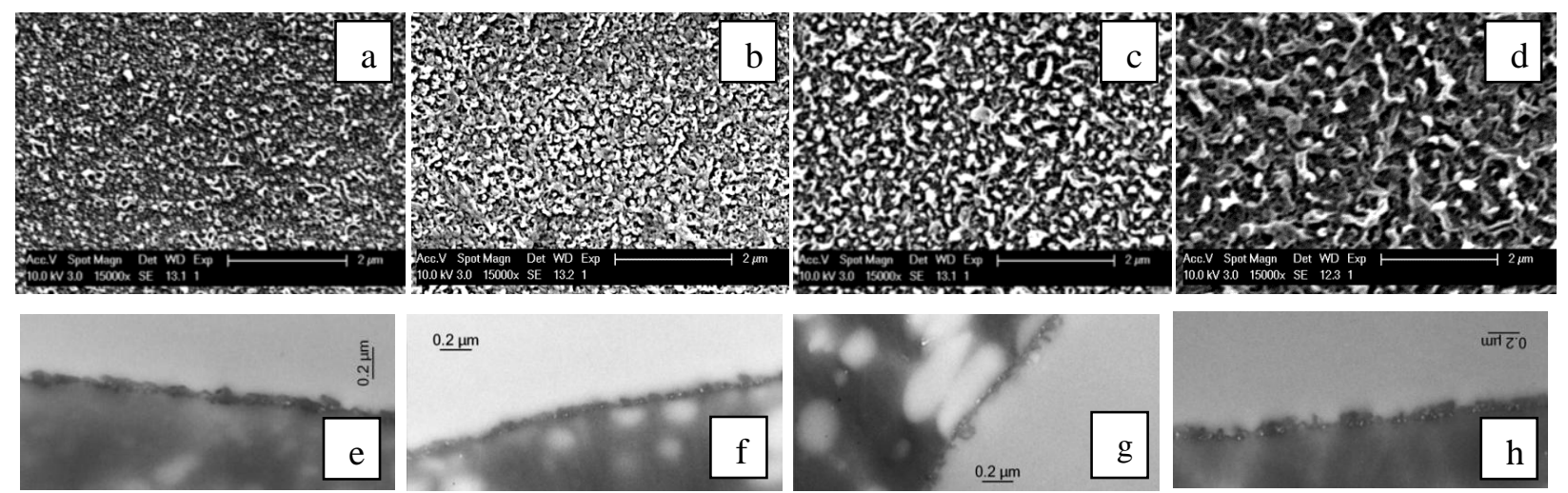

Figure 6: Surface SEM (above) and cross-section TEM images (below) of TFC PA membrane synthesized using the SIM method with various additives: (a)\&(e) without additives, (b)\&(f) with TEA, (c)\&(g) with SDS, (d)\&(h) with TEA and SDS. Synthesis conditions: 18\% PSf in casting solution, 2\% MPD in coagulation bath. 
Changes in the surface morphology can be associated with changes in the polymerization mechanism and as a consequence, in the membrane performance $[22,44]$. Therefore, the effect of the additives on the membrane morphology was further studied using electron microscopy.

From SEM images, a clear change in surface morphology can be observed (Figure 6a-d). Only the membrane prepared with both additives showed the pronounced characteristic 'ridge and valley' structure of a TFC PA membrane. The membranes prepared without additives and with only TEA added, had a rather 'grainy' surface morphology, as seen in Figure 6a and b. The addition of SDS to the coagulation bath leads to a different surface structure, which seems rougher when SDS is added (compare Figure $6 \mathrm{a}$ with $6 \mathrm{c}$ and $6 \mathrm{~b}$ with $6 \mathrm{~d}$ ). This is in agreement with the earlier statement that SDS alters the interfacial reaction zone. Although they show a different surface morphology, the performance of the membranes synthesized without additives and with only SDS in the aqueous phase is similar (see Figure 5). This indicates that additives can influence the top layer formation, but not necessarily affect the membrane performance. The active layer consist of an incipient dense PA base - mostly determining permeance and selectivity - with more loose PA on top [4, 34, 35]. It may thus be suggested that adding only SDS results in the formation of a similar incipient dense PA layer with more loose PA on top.

The active layer cross-section, as seen on TEM images (Figure 6e-h), seemed similar for all membranes. Moreover, the PA layer thicknesses were not significantly different. This was somewhat unexpected, since the membrane performance was altered using the various additives. However, Ghosh et al. argued that the entire PA film thickness is not intrinsically related to its water permeability and permeation occurs rather at the dense inner barrier layer [4].

From these experiments, it may be suggested that the addition of TEA+SDS affects mainly the incipient film formation and that adding SDS changes the overall PA morphology since it increases the contact area between the water and the organic phase during PA formation [43]. Although the addition of TEA or SDS separately did not hold an advantage, using both additives together clearly improved the performance of TFC PA membranes prepared via the SIM method. 


\subsubsection{PSf concentration}

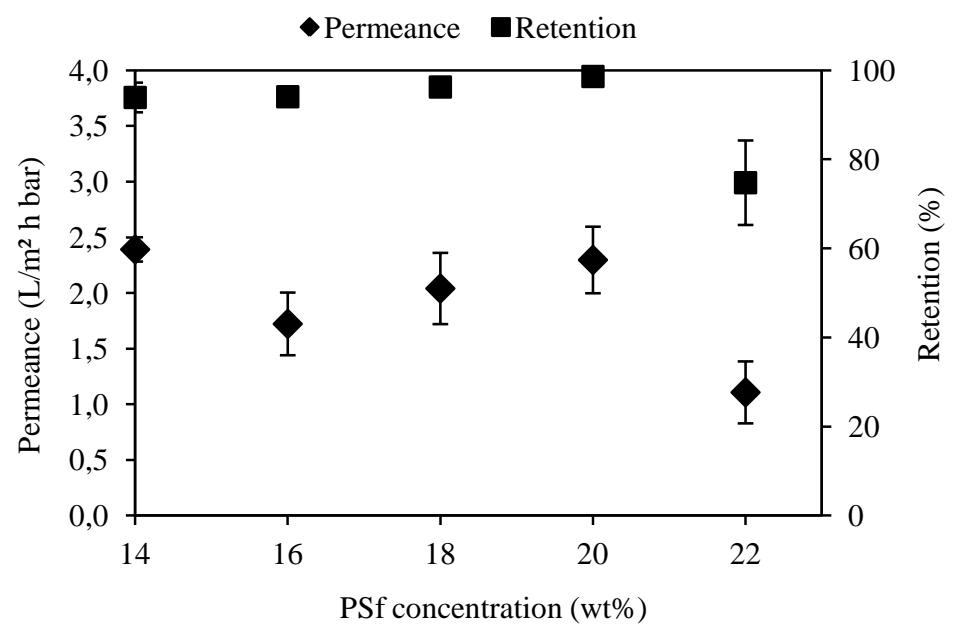

Figure 7: The effect of the PSf concentration in the casting solution of the support on the water permeance and salt retention of TFC membranes synthesized using the SIM method. Synthesis condition: 2 wt $\%$ MPD, 2 wt $\%$ TEA and $0.1 \mathrm{wt} \%$ SDS in the coagulation bath. Filtration conditions: $15 \mathrm{bar}, 1 \mathrm{~g} / \mathrm{L} \mathrm{MgSO}$.

Figure 7 presents the effect of the PSf concentration in the casting solution of the support membrane on the performance of the TFC PA membranes. Based on the trade-off between selectivity and permeance, it can be seen that the TFC PA membrane synthesized on a support cast from a $20 \mathrm{wt} \% \mathrm{PSf}$ solution gave the best performance. Increasing the PSf concentration to $22 \mathrm{wt} \%$ reduced the membrane performance, probably because the small pores and low porosity factor of the support inhibited the diffusion of MPD to the organic phase. This was verified by the different surface morphology of this membrane studied using SEM (Figure 8). Compared to the other membranes, a less pronounced ridge and valley structure was indeed present.
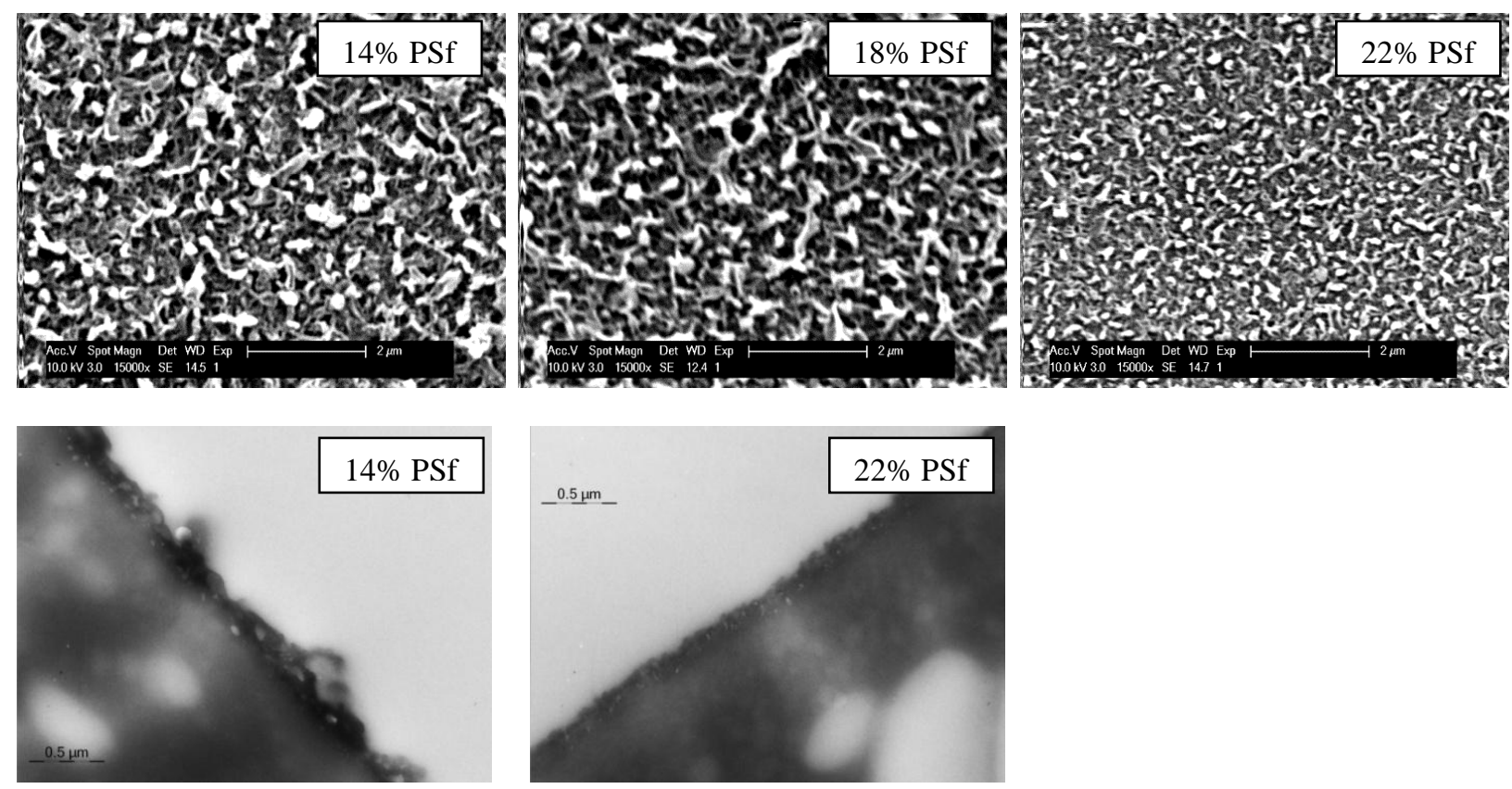
Figure 8: Surface SEM (above) and cross-section TEM images (below) of TFC PA membranes synthesized using the SIM method on supports cast from various PSf concentrations.

From Figure 7, it can be seen that even with as little as $14 \mathrm{wt} \%$ PSf in the casting solution of the support, the performance of the final TFC PA membrane was high: up to $96 \%$ retention compared to $99 \%$ using a $20 \mathrm{wt} \%$ PSf casting solution, while the permeance even increased compared to $16 \mathrm{wt} \%$ and $18 \mathrm{wt} \%$ PSf casting solutions. Moreover, the surface morphology was similar for all membranes synthesized using PSf concentrations below 22 wt\% (Figure 8). A TFC PA membrane synthesized using the POST method with $14 \mathrm{wt} \%$ PSf showed a selectivity of only $87 \%$ and permeance of $3.6 \mathrm{~L} \mathrm{~m}^{-1} \mathrm{~h}^{-1} \mathrm{bar}^{-1}$, which suggests a defective active layer. It was shown earlier that the PSf support morphology is not influenced by the use of the TFC additives in the coagulation bath. Therefore, these results indicate that by using the SIM method, it is possible to reduce the required PSf concentration for membrane synthesis compared to the POST method. The different performance of the final TFC membrane might be attributed to the different ways of trapping the MPD solution inside the solidified PSf support, hence, the way of impregnating a similar support with the amine solution.

When the PSf concentration was reduced further to 10 and $12 \mathrm{wt} \%$, it was difficult to consistently synthesize defect-free TFC membranes. Yet, membranes with respectively $85 \%$ and $86 \%$ retention were then obtained via the SIM method, compared with systematically less than $70 \%$ for the POST method.

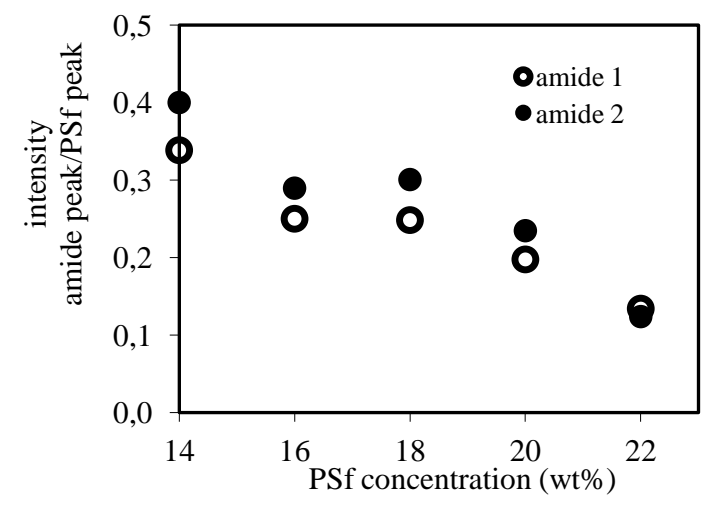

Figure 9: Ratio between the intensity of an amide and a PSf peak measured by ATR-FTIR for TFC PA membranes synthesized via the SIM method using various PSf concentrations in the casting solution of the support. The analyzed peaks were $1660 \mathrm{~cm}^{-1}$ for amide $1,1547 \mathrm{~cm}^{-1}$ for amide 2 and $1586 \mathrm{~cm}^{-1}$ for PSf.

Surprisingly, the ratio of the intensities between the amide and PSf peaks, based on ATR-FTIR spectra (Figure L in SI), increased with a decrease in the PSf concentration of the support membrane (Figure 9). Therefore, it is suggested that a more open structure of the support membrane promotes the diffusion of MPD toward the organic phase and consequently, the PA formation. The membranes prepared with 16, 18 and $20 \mathrm{wt} \%$ PSf show a rather similar ratio, which is lower than the one for $14 \mathrm{wt} \%$ PSf. The amount of PA slightly decreased, but was still high enough to produce a TFC membrane with a relatively high retention. Also, the surface 
morphology of these membranes was similar to the morphology of the membrane produced with only $14 \mathrm{wt} \%$ PSf, despite the lower ratios (Figure 8). Increasing the PSf concentration to $22 \mathrm{wt} \%$ resulted in an even lower ratio, which suggests that the PA formation decreased, in agreement with the assumption of less MPD diffusion throughout the thicker dense area above the macrovoids in this support. The TEM images in Figure 8 also show that the PA active layer of the TFC synthesized with $14 \mathrm{wt} \%$ PSf is slightly thicker and has a different morphology (more loose) compared to the TFCs synthesized with $22 \mathrm{wt} \%$ PSf and $18 \mathrm{wt} \%$ PSf (see Figure 6h).

An attempt was made to find examples in the literature of well-performing TFC PA membranes with supports synthesized from PSf solutions with low concentrations. It is noted that comparison between different studies was difficult due to the use of different PSf varieties (Udel P-3500, Udel P-1700, polyethersulfone,...), different solvents and additives in the casting solution (e.g. DMF, NMP, polyvinylpyrrolidone (PVP)) and the varying casting conditions (temperature, humidity, composition of the coagulation bath). Cadotte proposed the use of 15 wt\% Udel P-3500 in DMF for the preparation of the porous substrate [40]. Ghosh et al. applied a PSf concentration of $18 \mathrm{wt} \%$ (Mw 26000, Sigma-Aldrich) [4, 31]. Udel P-1700 PSf, which is used in this study, was previously applied in $15 \mathrm{wt} \%$ and $17 \mathrm{wt} \%$ casting solutions, which also contained PVP [45, 46]. Moreover, commercial PSf supports are often used for TFC studies, without much further information [37, 47]. However, to the best of our knowledge, reports mentioning the use of PSf concentrations below $15 \mathrm{wt} \%$ were not found.

\section{Conclusion}

A simplified method for the synthesis of TFC membranes via interfacial polymerization is presented. In this method, the amine monomer is added to the coagulation bath of the support layer, hence, phase inversion and impregnation of the support with monomer are realized simultaneously. A two step process is thus successfully simplified into one step.

Comparison with the traditionally used method indicated that, when standard synthesis conditions of the traditional method were used, the membrane performance was similar for both methods. With the SIM method, a good membrane performance was achieved by adding 2 wt $\%$ MPD (as the monomer), TEA and SDS (as a base/acylation catalyst and surfactant, respectively) to the coagulation bath and subsequently, immersing the cast polymer film in this bath for 5 min to undergo phase inversion and monomer impregnation. Lower MPD concentrations resulted in a thinner, less rough and not fully cross-linked top layer. Using MPD concentrations higher than 2 wt $\%$ did not improve the membrane performance. Adding both TEA and SDS to the coagulation bath, led to a strong increase in permeance and a small increase in retention of the TFC membrane. In addition, supports can now be cast from more dilute PSf concentrations to obtain a defect-free PA membrane with a good performance, thus holding an additional advantage in reducing the required amount of PSf. 
The simplified method thus results in a more efficient, time and material saving synthesis of TFC membranes, which is of potential interest from a commercial and environmental point of view. Moreover, difficulties encountered in the traditional method with incomplete wetting of the support layer during solvent and/or reagent exchanges can be avoided. This could lead to the synthesis of more homogeneous top layers and possibly to a better reproducibility during synthesis, hence, less chance of defects.

\section{Acknowledgements}

This work has been performed in the frame of the IAP 6/27 Functional Supramolecular Systems of the Belgian Federal Government. The authors are grateful to KU Leuven for support under the Methusalem grant CASAS and OT/11/061. Also, we wish to thank the Laboratory for Entomology of KU Leuven for chemicals and procedures for TEM, A. Volodin from the Laboratory of Solid-State Physics and Magnetism of KU Leuven for the water immersed AFM images and O. Steenhaut and A. Hubin from the Research Group Electrochemical and Surface Engineering of the Vrije Universiteit Brussel (VUB) for the XPS measurements.

\section{References}

[1] R.J. Petersen, Composite reverse osmosis and nanofiltration membranes, J. Membr. Sci., 83 (1993) 81-150.

[2] W.J. Lau, A.F. Ismail, N. Misdan, M.A. Kassim, A recent progress in thin film composite membrane: A review, Desalination, 287 (2012) 190-199.

[3] K.P. Lee, T.C. Arnot, D. Mattia, A review of reverse osmosis membrane materials for desalinationDevelopment to date and future potential, J. Membr. Sci., 370 (2011) 1-22.

[4] A.K. Ghosh, B.-H. Jeong, X. Huang, E.M.V. Hoek, Impacts of reaction and curing conditions on polyamide composite reverse osmosis membrane properties, J. Membr. Sci., 311 (2008) 34-45.

[5] A. Prakash Rao, N.V. Desai, R. Rangarajan, Interfacially synthesized thin film composite RO membranes for seawater desalination, J. Membr. Sci., 124 (1997) 263-272.

[6] A. Prakash Rao, S.V. Joshi, J.J. Trivedi, C.V. Devmurari, V.J. Shah, Structure-performance correlation of polyamide thin film composite membranes: effect of coating conditions on film formation, J. Membr. Sci., 211 (2003) 13-24.

[7] G.Z. Ramon, M.C.Y. Wong, E.M.V. Hoek, Transport through composite membrane, part 1: Is there an optimal support membrane?, J. Membr. Sci., 415-416 (2012) 298-305.

[8] P.S. Singh, S.V. Joshi, J.J. Trivedi, C.V. Devmurari, A.P. Rao, P.K. Ghosh, Probing the structural variations of thin film composite RO membranes obtained by coating polyamide over polysulfone membranes of different pore dimensions, J. Membr. Sci., 278 (2006) 19-25. 
[9] G.-Y. Chai, W.B. Krantz, Formation and characterization of polyamide membranes via interfacial polymerization, J. Membr. Sci., 93 (1994) 175-192.

[10] S.-Y. Kwak, S.G. Jung, S.H. Kim, Structure-Motion-Performance Relationship of Flux-Enhanced Reverse Osmosis (RO) Membranes Composed of Aromatic Polyamide Thin Films, Environ. Sci. Technol., 35 (2001) 4334-4340.

[11] B.J.A. Tarboush, D. Rana, T. Matsuura, H.A. Arafat, R.M. Narbaitz, Preparation of thin-filmcomposite polyamide membranes for desalination using novel hydrophilic surface modifying macromolecules, J. Membr. Sci., 325 (2008) 166-175.

[12] G.Z. Ramon, E.M.V. Hoek, Transport through composite membranes, part 2: Impacts of roughness on permeability and fouling, J. Membr. Sci., 425-426 (2013) 141-148.

[13] E.M. Vrijenhoek, S. Hong, M. Elimelech, Influence of membrane surface properties on initial rate of colloidal fouling of reverse osmosis and nanofiltration membranes, J. Membr. Sci., 188 (2001) 115-128.

[14] J.E. Tomaschke, Interfacially synthesized reverse osmosis membrane containing an amine salt and processes for preparing the same, US Patent 4,872,984 (1989).

[15] N.K. Saha, S.V. Joshi, Performance evaluation of thin film composite polyamide nanofiltration membrane with variation in monomer type, J. Membr. Sci., 342 (2009) 60-69.

[16] C.Y. Tang, Y.-N. Kwon, J.O. Leckie, Probing the nano- and micro-scales of reverse osmosis membranes - A comprehensive characterization of physiochemical properties of uncoated and coated membranes by XPS, TEM, ATR-FTIR, and streaming potential measurements, J. Membr. Sci., 287 (2007) 146-156.

[17] C.Y. Tang, Y.-N. Kwon, J.O. Leckie, Effect of membrane chemistry and coating layer on physiochemical properties of thin film composite polyamide RO and NF membranes: I. FTIR and XPS characterization of polyamide and coating layer chemistry, Desalination, 242 (2009) 149-167.

[18] S.A. Sundet, Production of composite membranes, US Patent 4,520,044 (1985).

[19] P. Vandezande, L.E.M. Gevers, J.S. Paul, I.F.J. Vankelecom, P.A. Jacobs, High throughput screening for rapid development of membranes and membrane processes, J. Membr. Sci., 250 (2005) 305310.

[20] A. Cano-Odena, M. Spilliers, T. Dedroog, K. De Grave, J. Ramon, I.F.J. Vankelecom, Optimization of cellulose acetate nanofiltration membranes for micropollutant removal via genetic algorithms and high throughput experimentation, J. Membr. Sci., 366 (2011) 25-32.

[21] High Throughput Membrane Systems Leuven, www.html-membrane.be (2013).

[22] S. Hermans, R. Bernstein, A. Volodin, I.F.J. Vankelecom, Systematic study of synthesis parameters and active layer morphology of interfacially polymerized polyamide-polysulfone membranes, and their effect on performance, Submitted to Desalination, (2013). 
[23] A.K. Holda, B. Aernouts, W. Saeys, I.F.J. Vankelecom, Study of polymer concentration and evaporation time as phase inversion parameters for polysulfone-based SRNF membranes, J. Membr. Sci., 442 (2013) 196-205.

[24] R.M. Boom, I.M. Wienk, T. van den Boomgaard, C.A. Smolders, Microstructures in phase inversion membranes. Part 2. The role of a polymeric additive, J. Membr. Sci., 73 (1992) 277-292.

[25] P. Aerts, E. Van Hoof, R. Leysen, I.F.J. Vankelecom, P.A. Jacobs, Polysulfone-Aerosil composite membranes: Part 1. The influence of the addition of Aerosil on the formation process and membrane morphology, J. Membr. Sci., 176 (2000) 63-73.

[26] B. Chakrabarty, A.K. Ghoshal, M.K. Purkait, Effect of molecular weight of PEG on membrane morphology and transport properties, J. Membr. Sci., 309 (2008) 209-221.

[27] J.-H. Kim, K.-H. Lee, Effect of PEG additive on membrane formation by phase inversion, J. Membr. Sci., 138 (1998) 153-163.

[28] M.-J. Han, S.-T. Nam, Thermodynamic and rheological variation in polysulfone solution by PVP and its effect in the preparation of phase inversion membrane, J. Membr. Sci., 202 (2002) 55-61.

[29] A. Mansourizadeh, A.F. Ismail, Effect of additives on the structure and performance of polysulfone hollow fiber membranes for CO2 absorption, J. Membr. Sci., 348 (2010) 260-267.

[30] G.R. Guillen, Y. Pan, M. Li, E.M.V. Hoek, Preparation and Characterization of Membranes Formed by Nonsolvent Induced Phase Separation: A Review, Ind. Eng. Chem. Res., 50 (2011) 3798-3817.

[31] A.K. Ghosh, E.M.V. Hoek, Impacts of support membrane structure and chemistry on polyamidepolysulfone interfacial composite membranes, J. Membr. Sci., 336 (2009) 140-148.

[32] R. Bernstein, S. Belfer, V. Freger, Surface Modification of Dense Membranes Using Radical Graft Polymerization Enhanced by Monomer Filtration, Langmuir, 26 (2010) 12358-12365.

[33] R. Bernstein, S. Belfer, V. Freger, Bacterial Attachment to RO Membranes Surface-Modified by Concentration-Polarization-Enhanced Graft Polymerization, Environ. Sci. Technol., 45 (2011) 59735980.

[34] F.A. Pacheco, I. Pinnau, M. Reinhard, J.O. Leckie, Characterization of isolated polyamide thin films of RO and NF membranes using novel TEM techniques, J. Membr. Sci., 358 (2010) 51-59.

[35] V. Freger, Kinetics of Film Formation by Interfacial Polycondensation, Langmuir, 21 (2005) 18841894.

[36] T.D. Matthews, H. Yan, D.G. Cahill, O. Coronell, B.J. Mariñas, Growth dynamics of interfacially polymerized polyamide layers by diffuse reflectance spectroscopy and Rutherford backscattering spectrometry, J. Membr. Sci., 429 (2013) 71-80.

[37] W. Xie, G.M. Geise, B.D. Freeman, H.-S. Lee, G. Byun, J.E. McGrath, Polyamide interfacial composite membranes prepared from m-phenylene diamine, trimesoyl chloride and a new disulfonated diamine, J. Membr. Sci., 403-404 (2012) 152-161. 
[38] V. Freger, Nanoscale Heterogeneity of Polyamide Membranes Formed by Interfacial Polymerization, Langmuir, 19 (2003) 4791-4797.

[39] V. Freger, S. Srebnik, Mathematical model of charge and density distributions in interfacial polymerization of thin films, J. Appl. Polym. Sci., 88 (2003) 1162-1169.

[40] J.E. Cadotte, Interfacially synthesized reverse osmosis membrane, US Patent 4,277,344 (1981).

[41] C. Klaysom, S. Hermans, A. Gahlaut, S. Van Craenenbroeck, I.F.J. Vankelecom, Polyamide/Polyacrylonitrile (PA/PAN) thin film composite osmosis membranes: Film optimization, characterization and performance evaluation, J. Membr. Sci., 445 (2013) 25-33.

[42] M. Dalwani, N.E. Benes, G. Bargeman, D. Stamatialis, M. Wessling, Effect of pH on the performance of polyamide/polyacrylonitrile based thin film composite membranes, J. Membr. Sci., 372 (2011) 228-238.

[43] M.J. Rosen, Surfactants and interfacial phenomena, 2nd ed., John Wiley \& Sons, New York, 1989.

[44] S. Veríssimo, K.V. Peinemann, J. Bordado, Influence of the diamine structure on the nanofiltration performance, surface morphology and surface charge of the composite polyamide membranes, J. Membr. Sci., 279 (2006) 266-275.

[45] C.K. Kim, J.H. Kim, I.J. Roh, J.J. Kim, The changes of membrane performance with polyamide molecular structure in the reverse osmosis process, J. Membr. Sci., 165 (2000) 189-199.

[46] I.J. Roh, S.Y. Park, J.J. Kim, C.K. Kim, Effects of the polyamide molecular structure on the performance of reverse osmosis membranes, J. Polym. Sci., Part B: Polym. Phys., 36 (1998) 1821-1830.

[47] J. Jegal, S.G. Min, K.-H. Lee, Factors affecting the interfacial polymerization of polyamide active layers for the formation of polyamide composite membranes, J. Appl. Polym. Sci., 86 (2002) 2781-2787. 


\section{Supplementary information}
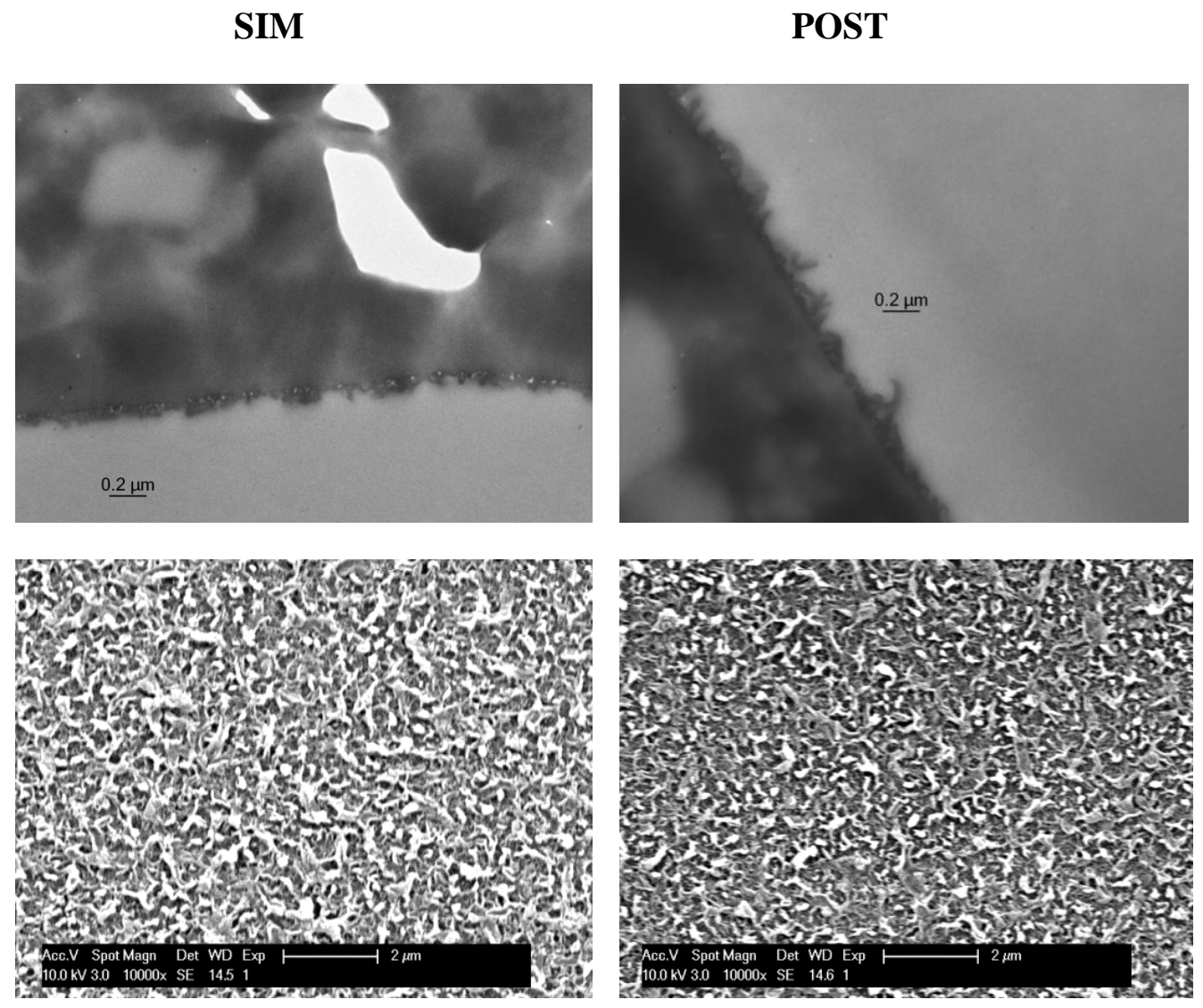

Figure A: Cross-section TEM (above) and top view SEM (below) images of TFC membranes prepared via the SIM and POST method. Synthesis conditions: 18 wt $\%$ PSf in casting solution, 2 wt $\%$ MPD, 2 wt $\%$ TEA and 0.1 wt $\%$ SDS in aqueous solution.

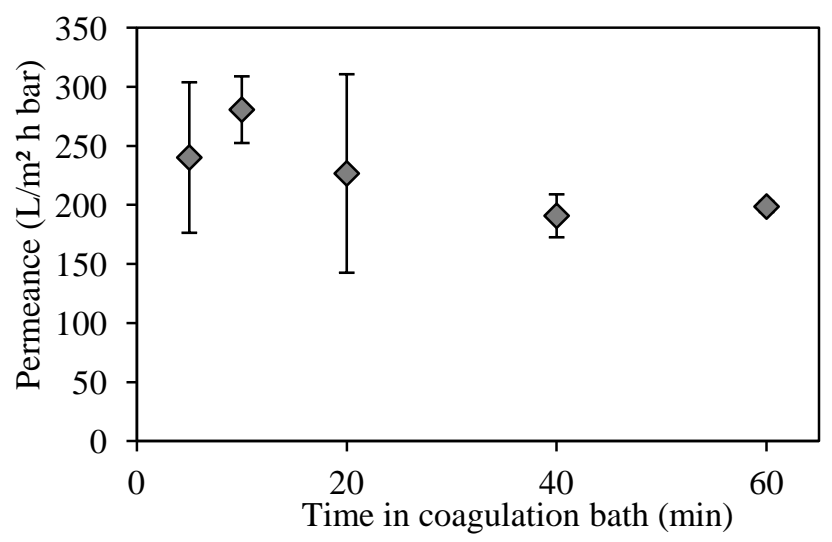

Figure B: Water permeance of PSf membranes synthesized with different residence times in the coagulation bath. Synthesis conditions: $18 \mathrm{wt} \%$ PSf in casting solution, $2 \mathrm{wt} \%$ MPD, $2 \mathrm{wt} \%$ TEA and $0.1 \mathrm{wt} \%$ SDS in coagulation bath. Filtration condition: 1 bar. 

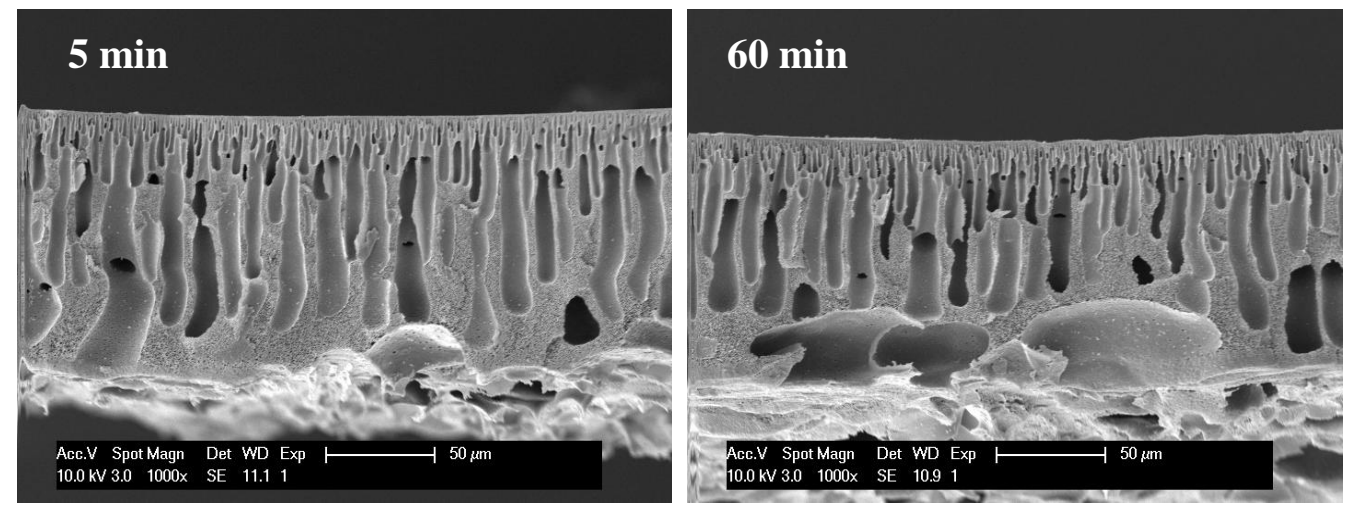

Figure C: Cross-section SEM images of PSf membranes synthesized with different residence times in the coagulation bath. Synthesis conditions: $18 \mathrm{wt} \%$ PSf in casting solution, $2 \mathrm{wt} \%$ MPD, $2 \mathrm{wt} \%$ TEA and $0.1 \mathrm{wt} \%$ SDS in coagulation bath.

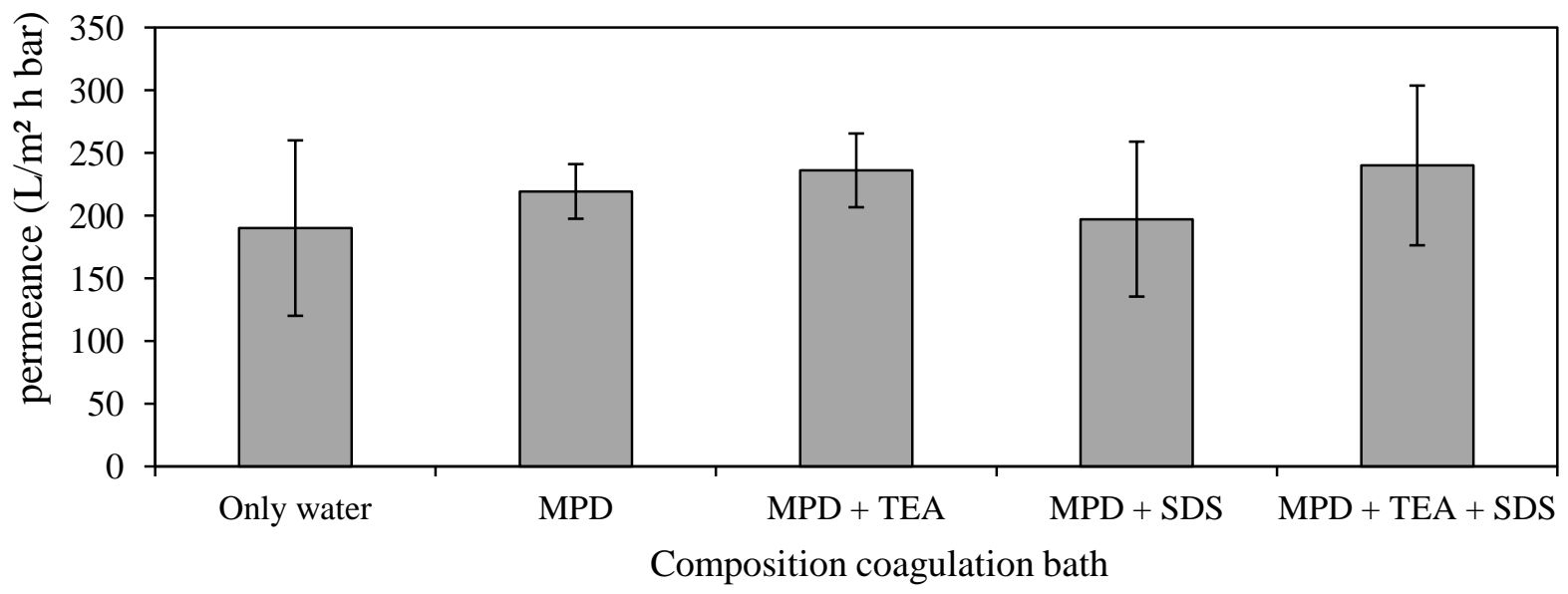

Figure D: Water permeance of PSf membranes synthesized with different components in the coagulation bath. Synthesis conditions: 18 wt\% PSf in casting solution. Filtration condition: 1 bar. 


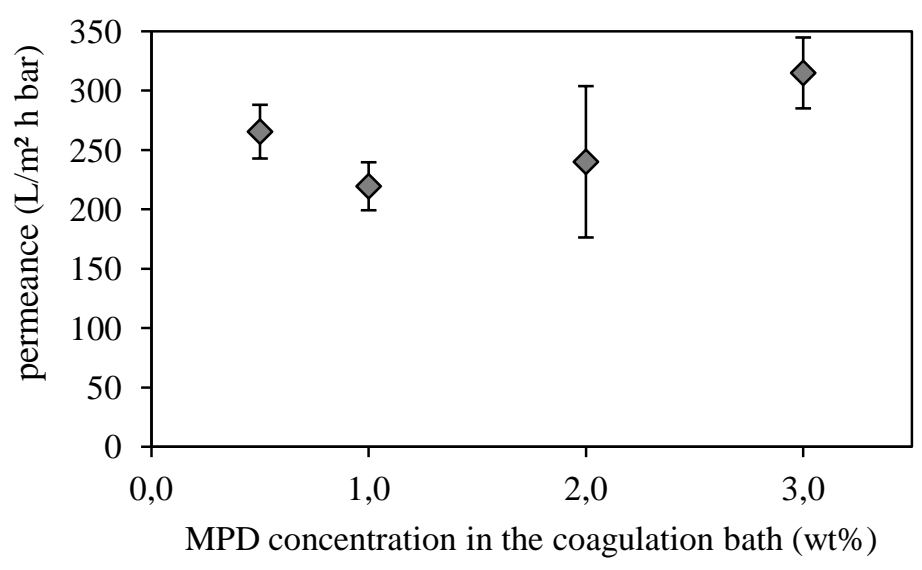

Figure E: Water permeance of PSf membranes synthesized with different MPD concentrations in the coagulation bath. Synthesis conditions: 18 wt\% PSf in casting solution, ratio of MPD/TEA/SDS 2/2/0,1. Filtration condition: 1 bar.

MPD

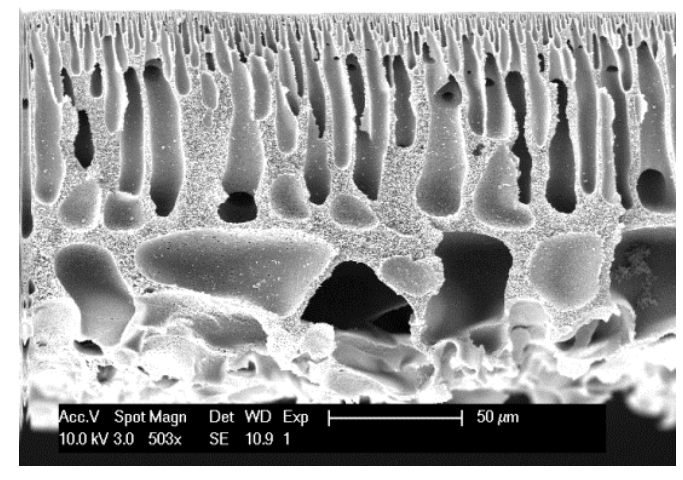

MPD + SDS



MPD + TEA

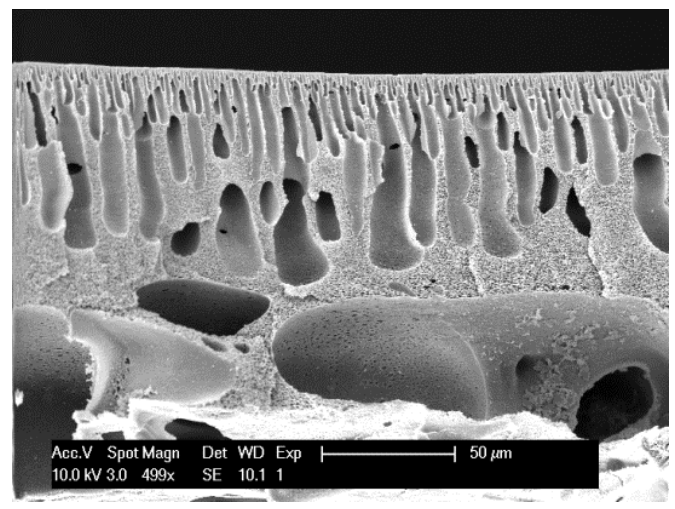

MPD + TEA + SDS

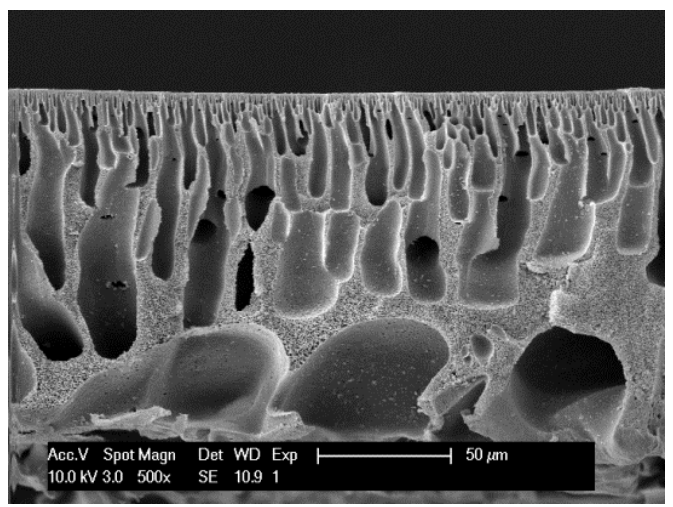

Figure F: Cross-section SEM images of PSf membranes synthesized with different components in the coagulation bath. Synthesis conditions: $18 \mathrm{wt} \%$ PSf in casting solution. 

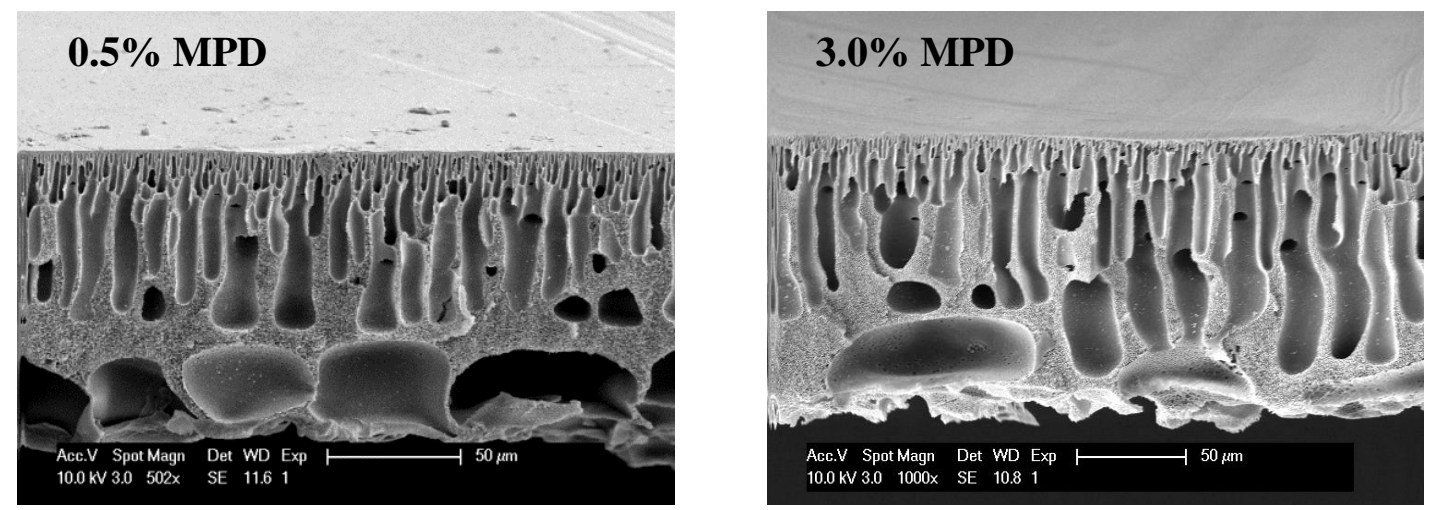

Figure G: Cross-section SEM images of PSf membranes synthesized with different MPD concentrations in the coagulation bath. Synthesis conditions: $18 \mathrm{wt} \%$ PSf in casting solution, ratio of MPD/TEA/SDS 2/2/0,1.

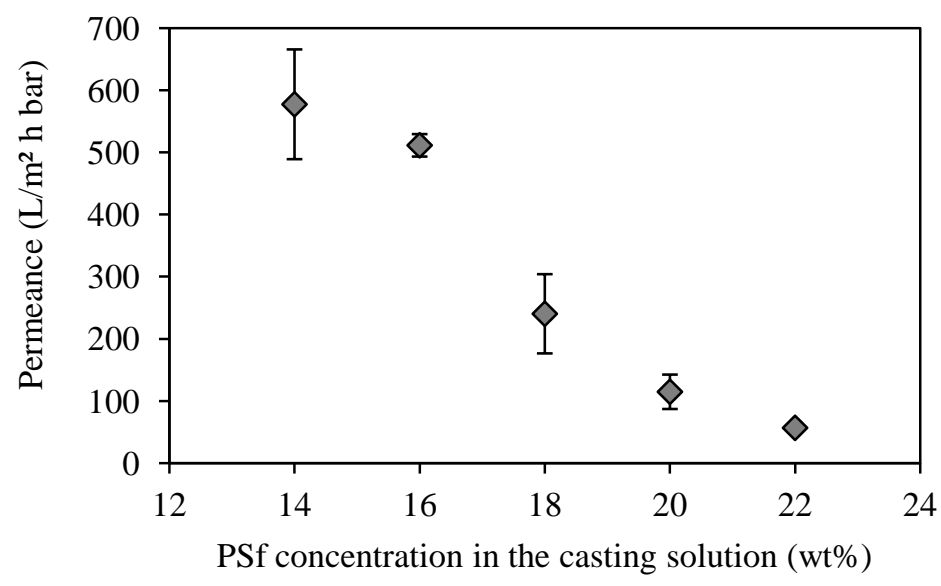

Figure H: Water permeance of PSf membranes synthesized from casting solutions with various PSf concentrations. Synthesis conditions: $2 \mathrm{wt} \%$ MPD, $2 \mathrm{wt} \%$ TEA and $0.1 \mathrm{wt} \%$ SDS in coagulation bath. Filtration condition: 1 bar. 



Figure I: Cross-section SEM images of TFC PA PSf membranes synthesized from casting solutions with various PSf concentrations. Synthesis conditions: $2 \mathrm{wt} \%$ MPD, 2 wt $\%$ TEA and $0.1 \mathrm{wt} \%$ SDS in coagulation bath.

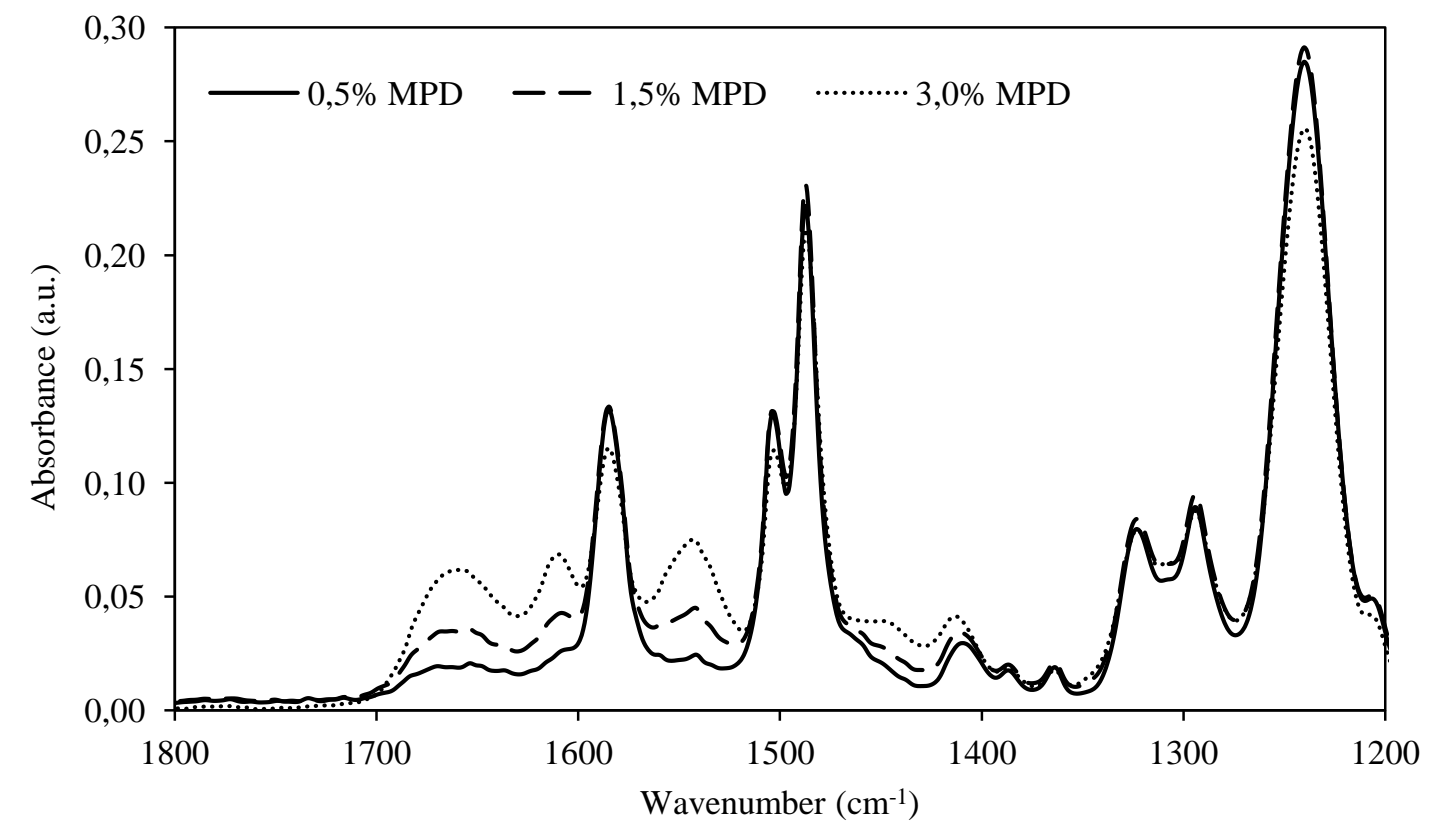

Figure J: ATR-FTIR spectra of TFC PA membranes synthesized with different MPD concentrations in the coagulation bath. Synthesis conditions: $18 \mathrm{wt} \%$ PSf in casting solution, ratio of MPD/TEA/SDS 2/2/0,1. 


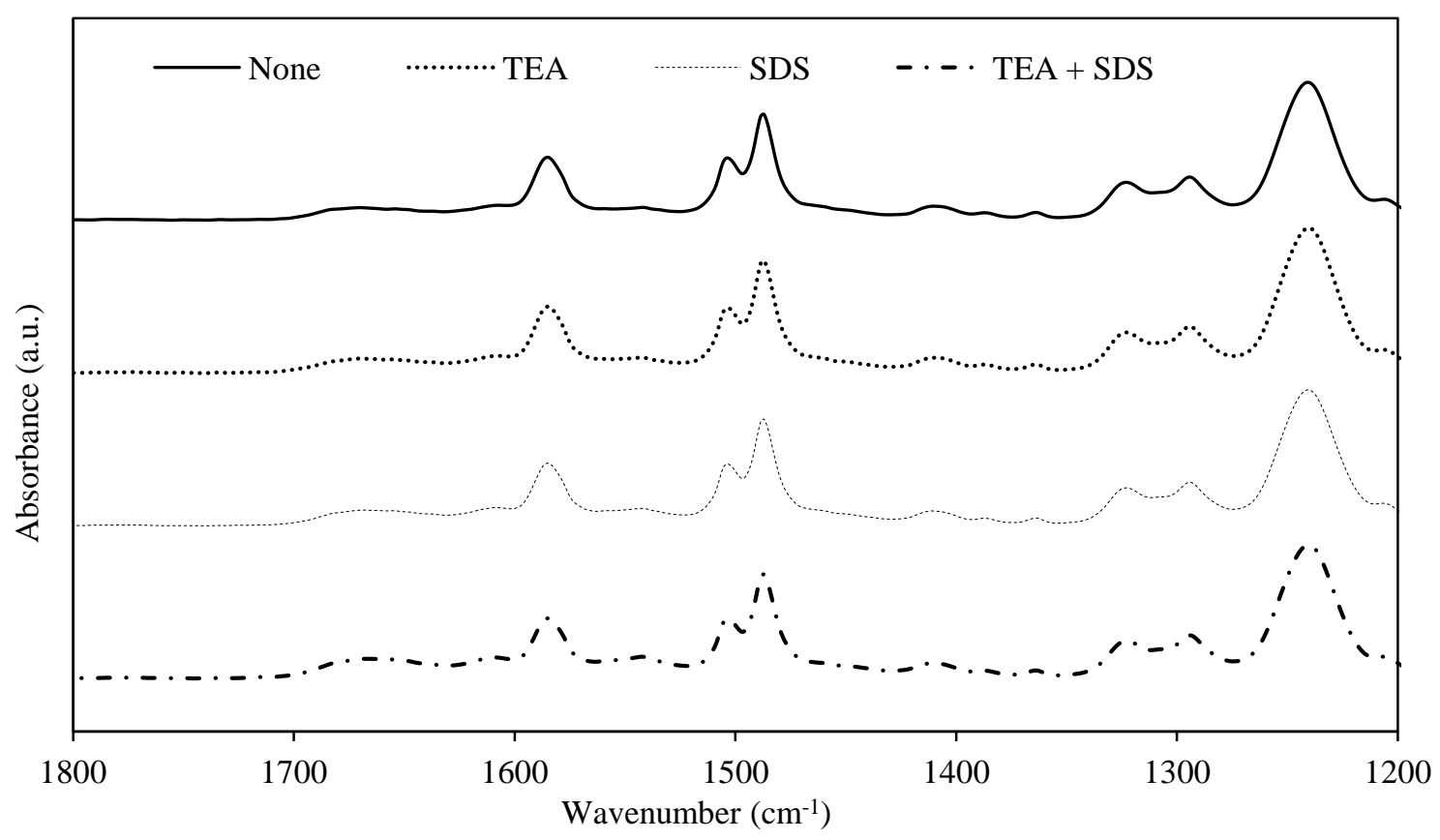

Figure K: ATR-FTIR spectra of TFC PA membranes synthesized via the SIM method with different components in the coagulation bath containing MPD (None, TEA, SDS and TEA+SDS).

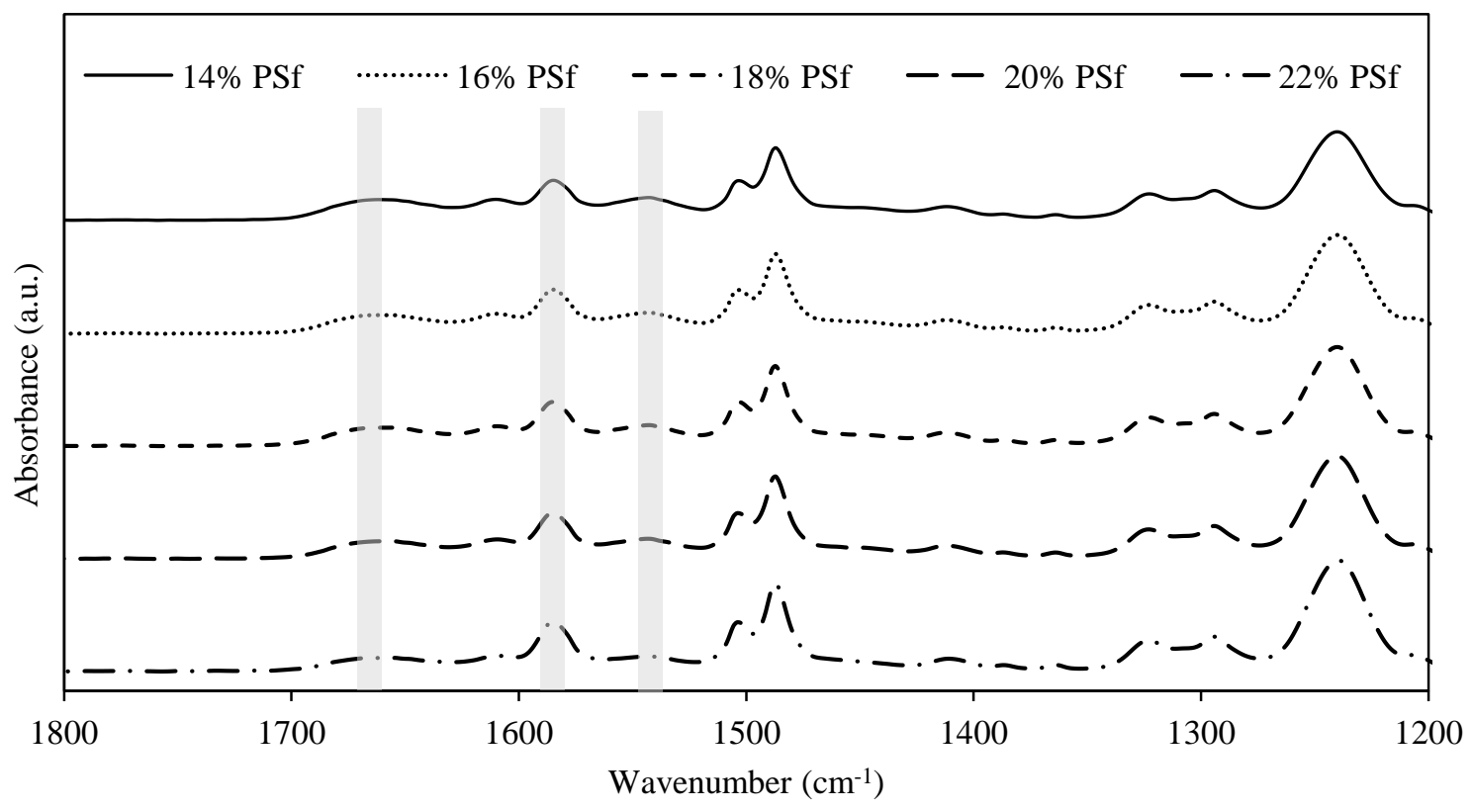

Figure L: ATR-FTIR spectra of TFC PA membranes synthesized via the SIM method from casting solutions with various PSf concentrations. Synthesis conditions: $2 \mathrm{wt} \%$ MPD, $2 \mathrm{wt} \%$ TEA and $0.1 \mathrm{wt} \%$ SDS in coagulation bath. The peaks used to construct Figure 9 are marked in grey $\left(1660 \mathrm{~cm}^{-1}\right.$ for amide $1,1586 \mathrm{~cm}^{-1}$ for PSf and $1547 \mathrm{~cm}^{-1}$ for amide 2. 